\title{
Calcium signalling-dependent mitochondrial dysfunction and bioenergetics regulation in respiratory chain Complex II deficiency
}

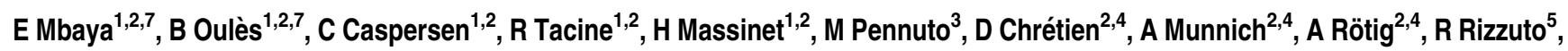 \\ GA Rutter ${ }^{6}$, P Paterlini-Bréchot ${ }^{1,2}$ and M Chami ${ }^{\star, 1,2,3}$
}

Despite advanced knowledge on the genetic basis of oxidative phosphorylation-related diseases, the molecular and/or cellular determinants for tissue-specific dysfunction are not completely understood. Here, we report the cellular events associated with mitochondrial respiratory Complex II deficiency occurring before cell death. Mutation or chronic inhibition of Complex II determined a large increase of basal and agonist-evoked $\mathrm{Ca}^{2+}$ signals in the cytosol and the mitochondria, in parallel with mitochondrial dysfunction characterized by membrane potential $\left(\Delta \psi_{\text {mit }}\right)$ loss, [ATP] reduction and increased reactive oxygen species production. Cytosolic and mitochondrial $\mathrm{Ca}^{2+}$ overload are linked to increased endoplasmic reticulum (ER) $\mathrm{Ca}^{2+}$ leakage, and to SERCA2b and PMCA proteasome-dependent degradation. Increased $\left[\mathrm{Ca}^{2+}\right]_{\text {mit }}$ is also contributed by decreased mitochondrial motility and increased ER-mitochondria contact sites. Interestingly, increased intracellular $\left[\mathrm{Ca}^{2+}\right]$ activated on the one hand a compensatory $\mathrm{Ca}^{2+}$-dependent glycolytic ATP production and determined on the second hand mitochondrial pathology. These results revealed the primary function for $\mathrm{Ca}^{2+}$ signalling in the control of mitochondrial dysfunction and cellular bioenergetics outcomes linked to respiratory chain Complex II deficiency.

Cell Death and Differentiation (2010) 17, 1855-1866; doi:10.1038/cdd.2010.51; published online 21 May 2010

Mitochondria are the driving force behind life, as mitochondrial oxidative phosphorylation provides the main source of ATP in the cell. In addition to energy production, mitochondria have a crucial function in mediating amino-acid biosynthesis, fatty acid oxidation, intermediate metabolic pathways, free radicals production and $\mathrm{Ca}^{2+}$ homeostasis. $^{1}$

Mitochondria affect intracellular $\mathrm{Ca}^{2+}$ metabolism in two ways: (i) directly by regulating both the amplitude, duration, location and propagation of cytosolic $\mathrm{Ca}^{2+}$ elevations and the recycling of $\mathrm{Ca}^{2+}$ towards the endoplasmic reticulum (ER) and $^{2}$ (ii) indirectly by producing ATP, which is used by $\mathrm{Ca}^{2+}$-dependent ATPases to pump $\mathrm{Ca}^{2+}$ out of the cell (by the plasma-membrane $\mathrm{Ca}^{2+}$ ATPase: PMCA) or into intracellular stores (by the sarco-ER $\mathrm{Ca}^{2+}$ ATPase: SERCA). Conversely, $\mathrm{Ca}^{2+}$ entering to the mitochondrial matrix regulates mitochondrial metabolism through the activation of the $\mathrm{Ca}^{2+}$-dependent enzymes of the Krebs cycle. ${ }^{3}$

Leigh's syndrome is a rare but severe and fatal encephalopathy of early childhood that is most frequently associated with deficiencies in nucleus-encoded subunits of Complex I (NDUFS3 and NDUFS7), ${ }^{4,5}$ Complex II (SDHA), ${ }^{6}$ Complex IV
$(\mathrm{SURF} 1)^{7}$ or pyruvate dehydrogenase. ${ }^{8}$ Despite the identification of the genetic origin of Leigh's syndrome, the molecular and cellular events associated with pathology are not completely understood.

Deregulations of intracellular $\mathrm{Ca}^{2+}$ signalling have been reported in different models of mitochondrial respiratory chain diseases, ${ }^{9-11}$ whereas data on Complex II deficiency are still lacking.

Complex II (succinate: ubiquinone (UQ) oxidoreductase) has a central function in oxidative metabolism, being an important enzyme of the citric acid cycle as well as a Complex of the mitochondrial respiratory chain. ${ }^{12}$

We report here the cellular events deriving from Complex II mutation associated with Leigh's syndrome. This study was conducted also in cellular models in which we mimicked Complex II deficiency by using Complex II inhibitors. We showed broad subcellular $\mathrm{Ca}^{2+}$ signalling alterations occurring before cell demise in Complex II-deficient cells. Interestingly, we showed that cytosolic and mitochondrial $\mathrm{Ca}^{2+}$ overload are linked to SERCA and PMCA degradation occurring in a proteasome-dependent manner. Our study also

\footnotetext{
${ }^{1}$ INSERM U 807, Paris, F-75015 France; ${ }^{2}$ Paris V University, Paris, F-75015 France; ${ }^{3}$ Department of Neuroscience and Brain Technology, The Italian Institute of Technology, Via Morego, 30, 16163, Genova, Italy; ${ }^{4}$ INSERM U 781, Paris, F-75015 France; ${ }^{5}$ Department of Experimental and Diagnostic Medicine, Section of General Pathology, University of Ferrara, 44100, Italy and ${ }^{6}$ Section of Cell Biology, Department of Medicine, Faculty of Medicine, Imperial College London, London SW72AZ, UK *Corresponding author: M Chami, Department of Neuroscience and Brain Technology, The Italian Institute of Technology, Via Morego 30, 16163, Genova, Italy. Tel: + 390107178 1566; Fax: + 3901072 0321; E-mail: mounia.chami@iit.it

${ }^{7}$ These authors contributed equally to this work.

Keywords: mitochondria; respiratory chain pathologies; calcium; bioenergetics; SERCA; PMCA

Abbreviations: $\mathrm{Ca}^{2+}$, calcium; Cyt, cytosol; $\left[\mathrm{Ca}^{2+}\right]_{\text {cyt }}$, cytosolic-free $\mathrm{Ca}^{2+}$ concentration; ER, endoplasmic reticulum; $\left[\mathrm{Ca}^{2+}\right]_{\mathrm{er}}$, endoplasmic reticulum $\mathrm{Ca}^{2+}$ concentration; $\left[\mathrm{Ca}^{2+}\right]_{\text {mit }}$, mitochondrial-free $\mathrm{Ca}^{2+}$ concentration; $\mathrm{IP}_{3}$, inositol 1, 4, 5-triphosphate; $\Delta \psi_{\mathrm{m}}$, mitochondrial potential; $[\text { ATP }]_{\text {mit, }}$ mitochondria ATP-free concentration; OXPHOS, oxidative phosphorylation; PMCA, plasma-membrane $\mathrm{Ca}^{2+}$ ATPase; ROS, reactive oxygen species; SERCA2, sarco-endoplasmic reticulum $\mathrm{Ca}^{2+}$ ATPase 2; SDHA, succinate dehydrogenase A subunit

Received 03.8.09; revised 29.3.10; accepted 09.4.10; Edited by B Zhivotovsky; published online 21.5.10
} 
revealed a dual function of $\mathrm{Ca}^{2+}$ deregulation in the control of cellular bioenergetics outcome and mitochondrial pathology.

\section{Results}

We studied fibroblasts isolated from a patient with Leigh's syndrome harbouring a homozygous Arg554Trp substitution in the Fp subunit of the Complex II $\left(\mathrm{SDHA}_{\mathrm{R} 554 \mathrm{~W}) .{ }^{13} \text { These }}\right.$ fibroblasts were shown to present a reduction of Complex II activity to $\sim 30 \%$ of control values. ${ }^{13}$ Leigh's syndrome associated with Complex II mutations was described in very rare cases. ${ }^{6}$ To bypass this limitation, we conducted the whole study using two inhibitors of Complex II (3-NP (3-nitropropionic acid) or Atpenin $\mathrm{A} 5^{14,15}$ ) in both fibroblasts derived from healthy individuals and the neuronal-derived cell line (SH-SY5Y). 3-NP is structurally similar to Complex II substrate succinate thus interacting with some residue in the active site of the enzyme. ${ }^{14}$ Atpenins were shown to share structural similarity with UQ thus blocking the electron transfer between the enzyme and $U Q$ by binding to a region that partly overlaps with the physiological UQ-binding site. ${ }^{15}$ To note, we deliberately used (i) concentrations of 3-NP $(300 \mu \mathrm{M})$ and Atpenin A5 (100 nM), which did not induce cell death at $20 \mathrm{~h}$ thus affording to study Complex II deficiency independently from cell death (Supplementary Figure S1a) and (ii) extended application (20 h) of the drugs to chronically inhibit Complex II (Supplementary Figure S1b). Importantly, under these conditions, Complex II activity was reduced to $15-40 \%$ of control values in both mutated cells and control fibroblasts and SH-SY5Y cells (Supplementary Figure S1b and Table S1). Application of 3-NP or Atpenin A5 at the same concentrations for $72 \mathrm{~h}$ or application of $1 \mathrm{mM} 3-\mathrm{NP}$ for $20 \mathrm{~h}$ determined cell death showing that Complex II inhibition is linked to cell death (Supplementary Figure S1c and 1d right).

To show that in our conditions we mimicked chronic Complex II inhibition on drug application, we measured Complex II activity at 6 and $20 \mathrm{~h}$ after treatment with $300 \mu \mathrm{M}$ 3-NP. Interestingly, reduction of Complex II activity occurred on $6 \mathrm{~h}$ of treatment and was maintained to a similar level on $20 \mathrm{~h}$ of treatment (data not shown).

We assessed mitochondrial functionality on Complex II mutation or inhibition. Mitochondrial potential $\left(\Delta \psi_{\text {mit }}\right)$ was measured by using tetramethyl rhodamine methyl ester (TMRM) dye, which accumulates within the mitochondrial matrix as a function of $\Delta \psi_{\text {mit. }}$. As expected, we observed a significant decrease ( $\sim 70 \%$ versus control considered as $100 \%$ ) of $\Delta \psi_{\text {mit }}$ on Complex II mutation or inhibition in both fibroblasts and SH-SY5Y cells (Figures 1a and b, respectively; Supplementary Table S2).

The mitochondrial respiratory chain is known to be the major source of reactive oxygen species (ROS) within the cell. ${ }^{16}$ We measured mitochondrial production of superoxide $\left(\mathrm{O}_{2}^{\bullet-}\right)$ by using MitoSOX red-mitochondrial superoxide indicator. Complex II-deficient cells displayed an increase in mitochondrial $\mathrm{O}_{2}^{\circ-}$ production of almost $25 \%$ as compared with control (Figure 1c; Supplementary Table S3). The specificity of the test was confirmed by using the ROS scavenger pyrrolidine dithiocarbamate (PDCT) (Figure 1c; Supplementary Table S3). This result is consistent with earlier reported data, which show increased activities of both mitochondrial and cytosolic inducible superoxide dismutase in $\mathrm{SDHA}_{\mathrm{R} 554 \mathrm{~W}}$ cells. ${ }^{17}$

Next, we analysed the impact of the mitochondrial Complex II defect on ATP level. Basal-mitochondrial ATP concentration $\left([\mathrm{ATP}]_{\text {mit }}\right)$ was measured using a luciferase probe targeted to the mitochondria (mitLuc). We observed a decreased basal $[A T P]_{\text {mit }}$ in $\mathrm{SDHA}_{\mathrm{R} 554 \mathrm{~W}}$-mutated fibroblasts $(74 \%$ of that in control cells) as well as in SH-SY5Y cells on Complex II inhibition (83\% in 3-NP and $77 \%$ in Atpenin A5 of that in control cells) (Figures 1d and e; Supplementary Table S4).

$\mathrm{Ca}^{2+}$ is an important regulator of mitochondrial function and acts at several levels within the organelle to stimulate OXPHOS. ${ }^{3}$ We measured subcellular $\mathrm{Ca}^{2+}$ signalling in fibroblasts and SH-SY5Y cells on Complex II mutation or inhibition. Measurement of basal $\left[\mathrm{Ca}^{2+}\right]_{\text {cyt }}$, by using the Fluo-4, AM dye, revealed a significant increase ( 2-4-fold) of basal $\left[\mathrm{Ca}^{2+}\right]_{\text {cyt }}$ in $\mathrm{SDHA}_{\mathrm{R} 554 \mathrm{~W}}$-mutated fibroblasts and in control fibroblasts on Complex II inhibition as compared with non-treated ones (Figure 2a; Supplementary Table S5). Similarly, we also observed an increase of basal $\left[\mathrm{Ca}^{2+}\right]_{\text {mit }}$ in $\mathrm{SDHA}_{\mathrm{R} 554 \mathrm{~W}}$-mutated fibroblasts and in control fibroblasts on Complex II inhibition ( 1.5-2-fold) as compared with non-treated cells as measured by X-Rhod-1, AM probe (Figure 2b; Supplementary Table S6).

We then analysed agonist-evoked cytosolic and mitochondrial $\mathrm{Ca}^{2+}$ signals using adenovirus-delivered recombinant aequorin $\mathrm{Ca}^{2+}$ probes (cytAEQ, mitAEQ, respectively).

By using the cytosolic aequorin probe, we showed a significant increase $(\sim 1.5-1.7$-fold) of the agonist-evoked cytosolic $\mathrm{Ca}^{2+}$ signal $\left(\left[\mathrm{Ca}^{2+}\right]_{\text {cyt }}\right)$ in $\mathrm{SDHA}_{\mathrm{R} 554 \mathrm{~W} \text {-mutated }}$ fibroblasts and SH-SY5Y cells on Complex II inhibition as compared with controls (Figure 2c; Supplementary Table S7).

By using the mitochondrial aequorin probe, we noticed a significant increase of agonist-evoked mitochondrial $\mathrm{Ca}^{2+}$ signal $\left(\left[\mathrm{Ca}^{2+}\right]_{\text {mit }}\right)$ in $\mathrm{SDHA}_{\mathrm{R} 554 \mathrm{~W}}$-mutated fibroblasts ( $\sim$-fold increase) and SH-SY5Y cells on Complex II inhibition ( $\sim 1.5$-fold increase) as compared with controls (Figure 2d; Supplementary Table S8).

Mitochondrial $\mathrm{Ca}^{2+}$ uptake and $\Delta \psi_{\text {mit }}$ are tightly crossregulated. ${ }^{1}$ On the one hand, the main driving force for $\mathrm{Ca}^{2+}$ accumulation across the inner mitochondrial membrane is the electrochemical gradient $(\Delta \mu \mathrm{H})$ established and maintained by the respiratory chain, whereas, on the other hand, depolarization occurs transiently after $\mathrm{Ca}^{2+}$ uptake in physiological conditions. ${ }^{1}$ We measured the kinetics of the $\mathrm{Ca}^{2+}$ and potential changes occurring in mitochondria of Complex II-deficient cells. Interestingly, we observed an increased agonist-evoked mitochondrial $\mathrm{Ca}^{2+}$ response as early as after $4 \mathrm{~h}$ of treatment with Complex II inhibitors (Figure 3a; Supplementary Table S8). This result was observed with both inhibitors 3-NP and Atpenin A5 and in both fibroblasts and SH-SY5Y cells (Figure 3a; Supplementary Table S8). In parallel, no modification of $\Delta \psi_{\text {mit }}$ was noticed in cells treated in the same conditions (Figure 3b; Supplementary Table S2). This result suggests that increase of mitochondrial $\mathrm{Ca}^{2+}$ uptake precedes the loss of $\Delta \psi_{\text {mit }}$ in Complex II-deficient cells.

We then investigated the mechanisms underlying increased $\left[\mathrm{Ca}^{2+}\right]$ associated with Complex II deficiency. As cytosolic and mitochondrial $\mathrm{Ca}^{2+}$ signals are largely dependent of $\mathrm{ER} \mathrm{Ca}^{2+}$ store, we measured the state of 
a
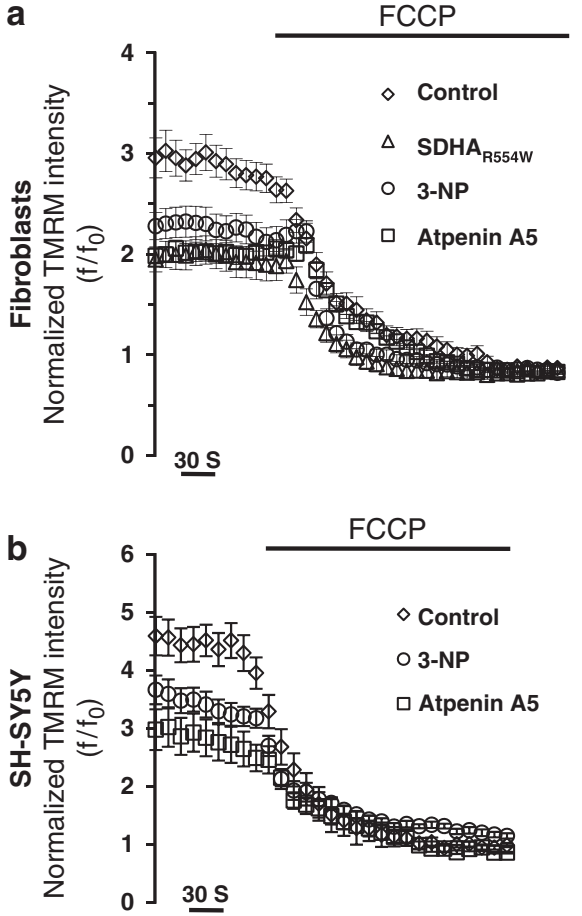

C

Fibroblasts
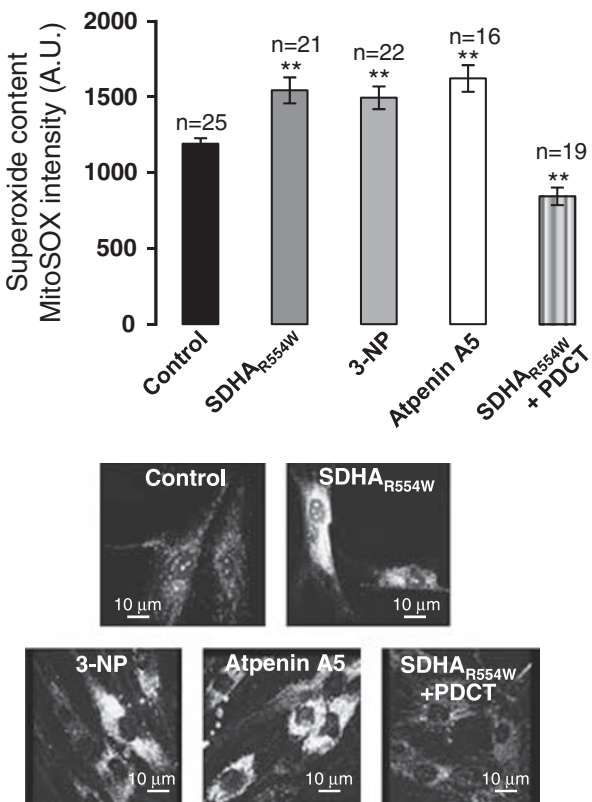

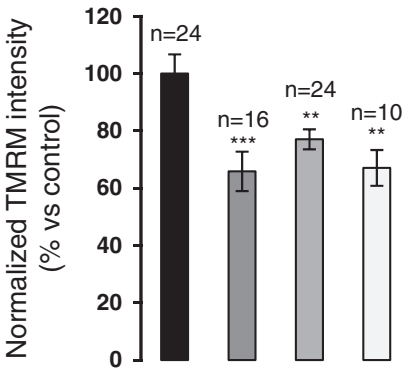

Control

$\square$ SDHA $_{\text {R554W }}$

$\square$ 3-NP

Atpenin A5
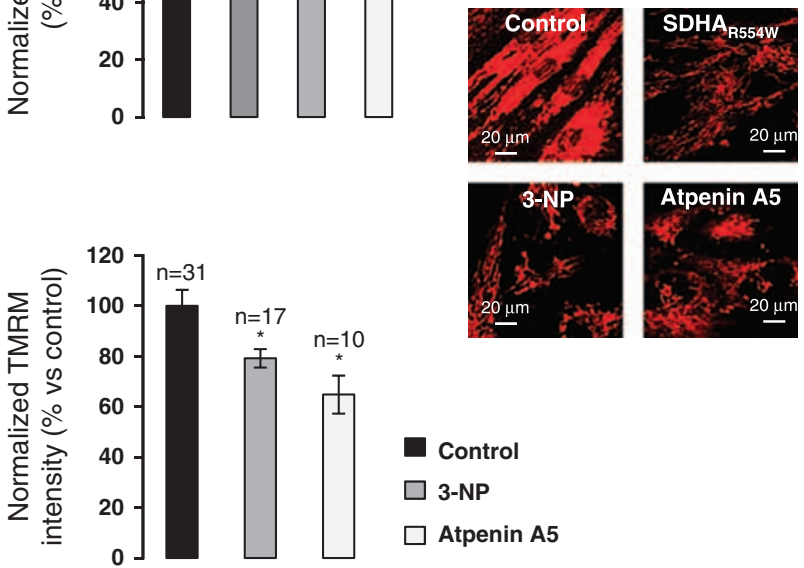

Control

$\square$ 3-NP

$\square$ Atpenin A5

\section{d \\ Fibroblasts}
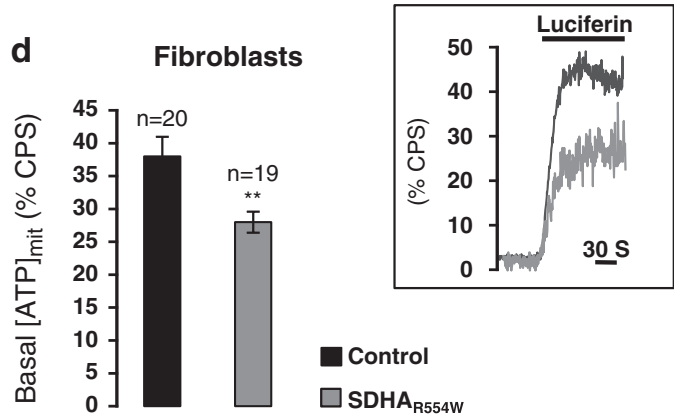

Control

$\square \mathrm{SDHA}_{\mathrm{R} 554 \mathrm{~W}}$

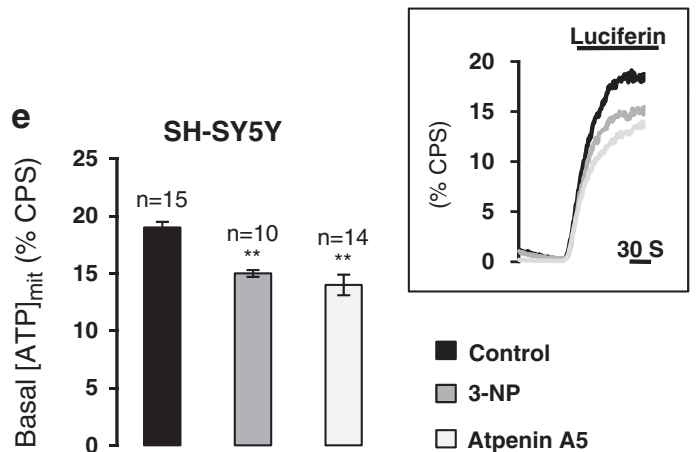

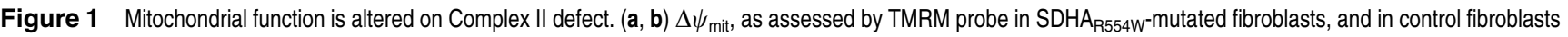
(a) and SH-SY5Y cells (b) left untreated (control) or treated with $300 \mu \mathrm{M}$ 3-NP or $100 \mathrm{nM}$ Atpenin A5 for $20 \mathrm{~h}$. Basal TMRM intensity was normalized to the fluorescence drop $\left(\Delta \psi_{\text {mit }}\right.$ collapse) on $10 \mu \mathrm{M}$ FCCP application. Representative traces show normalized $f f_{0}$ TMRM intensity, where $f$ is the basal TMRM intensity, and $f_{0}$ the TMRM intensity after FCCP application. Graphs show normalized TMRM $\left(f / f_{0}\right)$ intensity in percentage versus control considered as $100 \%$. Images are representative of TMRM loading in mutated fibroblasts and controls left untreated or treated as detailed before. The mean of normalized TMRM signal \pm S.E.M., normalized TMRM signal (\%) and the number of experiments are represented in Supplementary Table S2. (c) Superoxide content as determined with MitoSOX dye in SDHA $A_{\text {R554W }}$ fibroblasts, and in control fibroblasts left untreated (control) or treated as in (a). Representative images of MitoSOX loading are shown. The mean of MitoSOX intensity \pm S.E.M. and the number of experiments are represented in Supplementary Table S3. (d, e) Mitochondrial basal ATP level normalized to the maximum luciferase signal in SDHA $A_{\text {R554W }}$ and control fibroblasts (d) and in SH-SY5Y cells left untreated (control) or treated as in (a). (e) Data are expressed as percentage of luciferase light output (CPS: counts per second) with respect to the value obtained after cell permeabilization in the presence of maximal [ATP] (see Materials and methods for details). Representative traces of normalized luciferase signal (\% CPS) are shown in the insets. The mean of basal ATP level \pm S.E.M. and the number of experiments are represented in Supplementary Table S4. (a-e) Data are representative of three independent experiments. ${ }^{\star} P \geqslant 0.001,{ }^{* \star} P<0.001$ versus control 
a

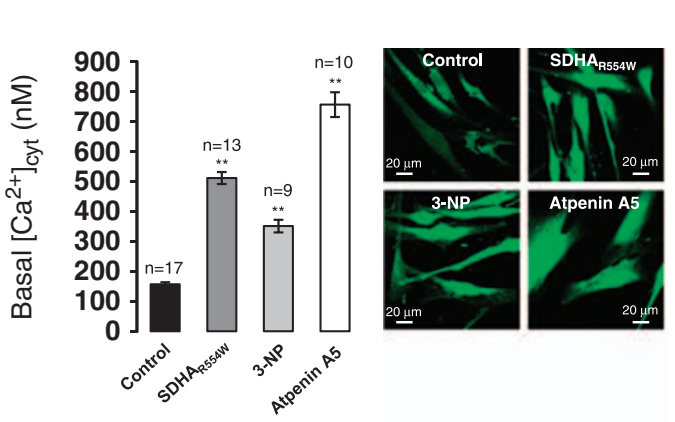

b

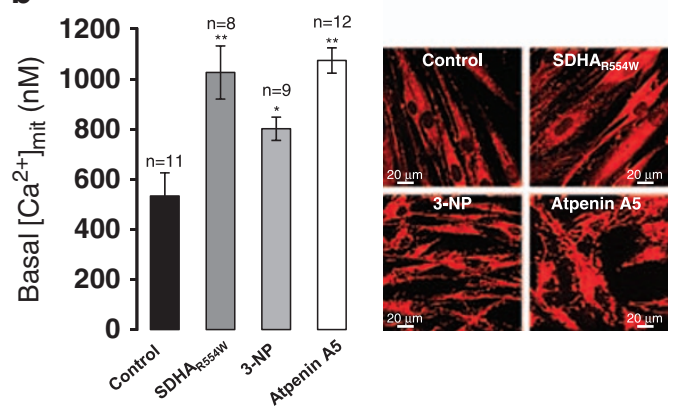

C

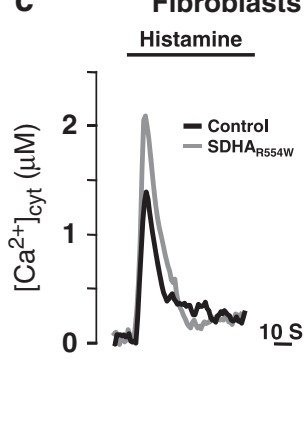

d

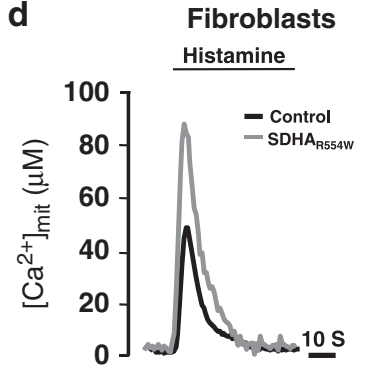

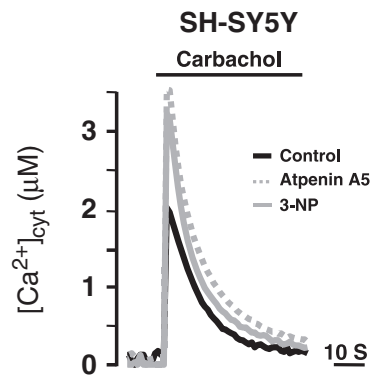

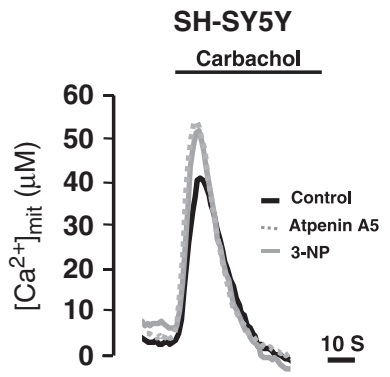

Figure 2 Complex II defect leads to cytosolic and mitochondrial $\mathrm{Ca}^{2+}$ signalling deregulation. (a, b) Basal cytosolic $\left[\mathrm{Ca}^{2+}\right.$ ] (calibrated Fluo-4, AM intensity, see Materials and methods for details) (a) and basal-mitochondrial $\left[\mathrm{Ca}^{2+}\right]$ (calibrated X-Rhod-1, AM intensity, see Materials and Methods for details) (b) in SDHA $\mathrm{R}_{554 \mathrm{~W}}$-mutated fibroblasts and in control fibroblasts left untreated (control) or treated as in Figure 1a. Representative images for Fluo-4, AM and X-Rhod-1, AM loading are shown. The mean value \pm S.E.M. and the number of experiments are indicated in Supplementary Tables S5 and S6. (c, d) Representative curves of agonist-evoked cytosolic Ca ${ }^{2+}$ signal $\left(\left[\mathrm{Ca}^{2+}\right]_{\mathrm{cyt}}\right)(\mathbf{c})$ and mitochondrial $\mathrm{Ca}^{2+}$ signal $\left(\left[\mathrm{Ca}^{2+}\right]_{\mathrm{mit}}\right)(\mathbf{d})$ in control and SDHA $\mathrm{R}_{554 \mathrm{~W}}$ fibroblasts (left panel) and in SH-SY5Y cells (right panel) left untreated (control) or treated as in Figure 1a. The mean values \pm S.E.M. and the number of experiments are indicated in Supplementary Tables S7 and S8. (a-d) Data are representative of three independent experiments. ${ }^{*} P \geqslant 0.001,{ }^{\star *} P<0.001$ versus control

$\mathrm{ER} \mathrm{Ca}^{2+}$ load by using the ER-targeted aequorin probe. $\mathrm{SDHA}_{\mathrm{R} 554 \mathrm{~W}}$ mutation determined a decrease of steady state ER-free $\mathrm{Ca}^{2+}\left(\left[\mathrm{Ca}^{2+}\right]_{\mathrm{ER}}\right)$ by almost $\sim 40 \%$ as compared with three different controls (Figure 4a; Supplementary Table S9). A slighter but significant decrease $(\sim 5 \%)$ of ER steady state was also obtained on Complex II inhibition by 3-NP and Atpenin A5 (Supplementary Figure S2a and Table S9). We then showed that $\mathrm{ER} \mathrm{Ca}^{2+}$ depletion is associated with decreased $\mathrm{ER} \mathrm{Ca}^{2+}$ uptake rate, and increased passive $\mathrm{ER} \mathrm{Ca}^{2+}$ leakage (Figures $4 \mathrm{~b}$ and $\mathrm{c}$, respectively). No modification of agonist-evoked $\mathrm{Ca}^{2+}$ release from the store was noticed between control and Complex II-deficient cells (Supplementary Figure S2b).

Earlier data have shown that $\mathrm{ER} \mathrm{Ca}^{2+}$ depletion can be linked to the induction of the unfolded protein response (UPR). ${ }^{18}$ However, our data revealed no induction of UPR in $\mathrm{SDHA}_{\mathrm{R} 554 \mathrm{~W}}$ cells (Supplementary Figure S3).

Finally, no clear modification of capacitative $\mathrm{Ca}^{2+}$ entry

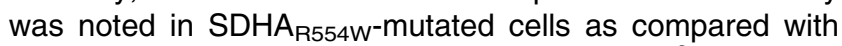
controls (Figure 4d) ruling out a change in $\mathrm{Ca}^{2+}$ influx in the observed $\left[\mathrm{Ca}^{2+}\right]_{\text {cyt }}$ and $\left[\mathrm{Ca}^{2+}\right]_{\text {mit }}$ increase.

These results may indicate that the increased cytosolic and mitochondrial agonist-evoked $\mathrm{Ca}^{2+}$ signals are largely linked to increased basal $\mathrm{Ca}^{2+}$ levels. This late event is likely due, at least in part, to decreased $\mathrm{ER} \mathrm{Ca}^{2+}$ store load and increased $\mathrm{ER} \mathrm{Ca}^{2+}$ emptying through increased $\mathrm{Ca}^{2+}$ leak.
To investigate the molecular mechanisms underlying the intracellular $\mathrm{Ca}^{2+}$ overload related to Complex II deficiency, we analysed SERCA and PMCA expression in Complex II-deficient cells by western blotting. SH-SY5Y cells are known to express mostly SERCA2b and PMCA2 isoforms. As shown in Figure 5a, a significant decrease of SERCA2b and PMCA2 expression was observed in $\mathrm{SDHA}_{\mathrm{R} 554 \mathrm{~W}}$ cells and in SH-SY5Y cells on Complex II inhibition (Figure 5a). Interestingly, a similar result was observed on inhibition of mitochondrial ATP synthase by Oligomycin (Figure 5a).

SERCA and PMCA down-regulation could be due to reduced transcription level or increased rate of degradation. By using semi-quantitative RT-polymerase chain reaction (PCR), we showed that SERCA2b and PMCA2 transcription level is not altered on Complex II or ATP synthase inhibition (Figure 5b). We then investigated SERCA2b and PMCA2 degradation. SH-SY5Y cells were treated with the protein synthesis inhibitor cyclohexemide $(\mathrm{CHX})$ in the presence or not of 3-NP or Oligomycin. Kinetic analyses revealed a rapid degradation of both SERCA2b and PMCA2 on Complex II or ATP synthase (Figure 5c) inhibition. To determine whether SERCA2b and PMCA are degraded by the proteasome, we treated the cells with the proteasome inhibitor MG132 for $2 \mathrm{~h}$ and then applied $\mathrm{CHX}$ alone or in the presence of $3-N P$ and Oligomycin for $1 \mathrm{~h}$. As shown in Figure $5 \mathrm{~d}$, treatment of the cells with MG132 prevented SERCA2b and 
a

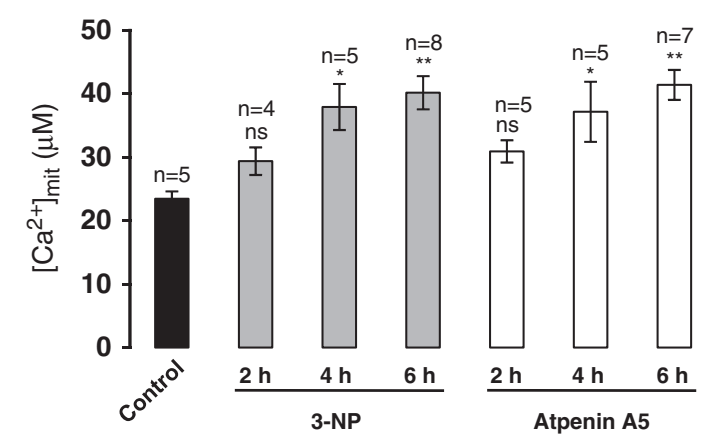

b

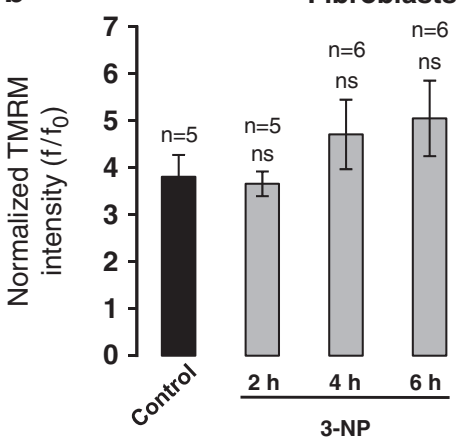

Fibroblasts

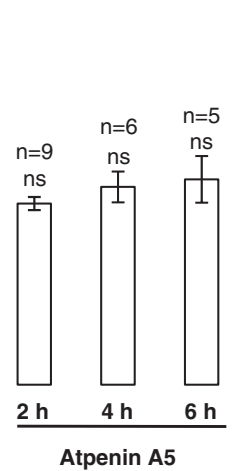

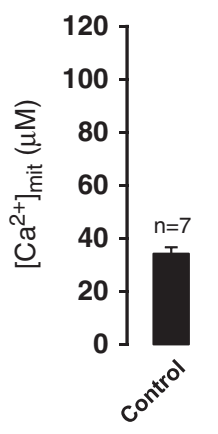
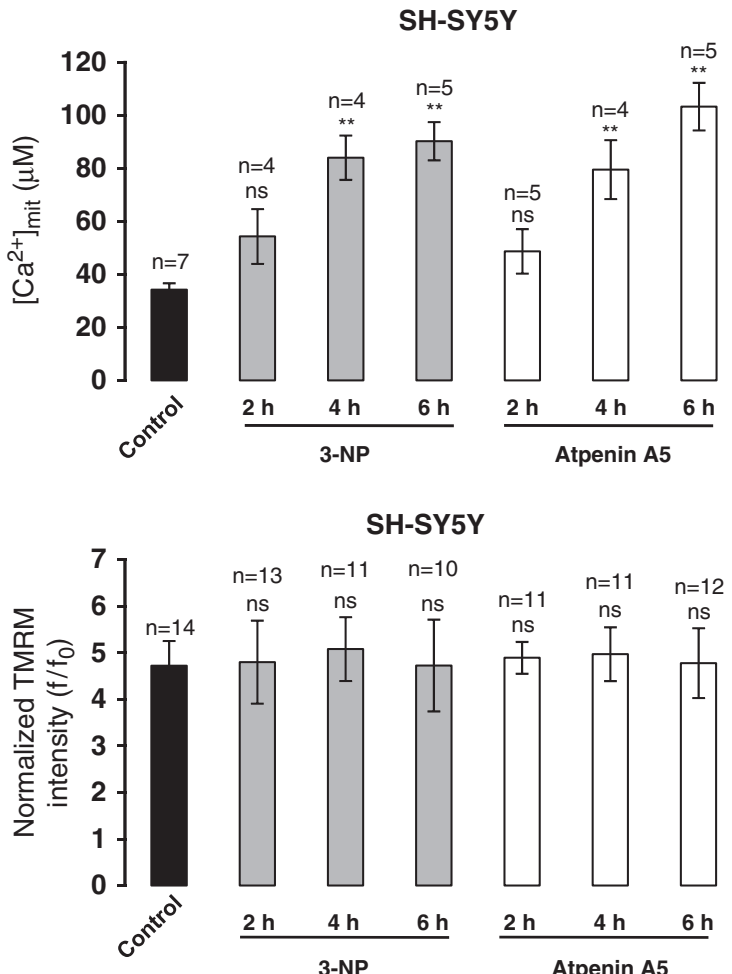

\section{SH-SY5Y}

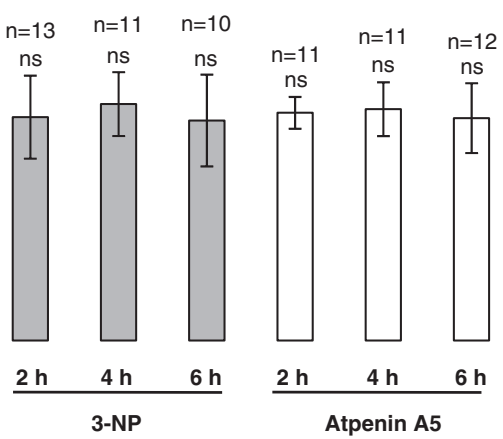

Figure 3 Mitochondrial $\mathrm{Ca}^{2+}$ overload occurs early on Complex II deficiency. (a) Agonist-evoked mitochondrial $\mathrm{Ca}^{2+}$ signal $\left(\left[\mathrm{Ca}^{2+}\right]_{\text {mit }}\right)$ in control fibroblasts and SH-SY5Y cells untreated (control) or treated with $300 \mu \mathrm{M}$ 3-NP or $100 \mathrm{nM}$ Atpenin A5 for 2, 4 or $6 \mathrm{~h}$. The mean values \pm S.E.M. and the number of experiments are indicated in Supplementary Table S8. (b) $\Delta \psi_{\text {mit, }}$ as performed in Figures $1 \mathrm{a}$ and b in control fibroblasts and SH-SY5Y cells untreated (control) or treated as in (a). Graphs show normalized TMRM intensity $\left(f / f_{0}\right)$. The mean $f / f_{0}$ values \pm S.E.M. and the number of experiments are represented in Supplementary Table S2. Data are representative of three independent experiments. ${ }^{*} P \geqslant 0.001,{ }^{\star \star} P<0.001$ versus control

PMCA2 degradation on Complex II or ATP synthase inhibition (Figure 5d).

These data reveal the involvement of the proteasomedependent degradation pathway in SERCA2b and PMCA2 down-regulation. The result obtained on ATP synthase blockade by Oligomycin may reveal that rapid degradation of SERCA2b and PMCA2 is an ATP-dependent mechanism. Overall, these data suggests that cytosolic and mitochondrial $\mathrm{Ca}^{2+}$ overload on Complex II deficiency are a consequence of suppressed cytosolic $\mathrm{Ca}^{2+}$ extrusion through the plasma membrane and accumulation in the ER by PMCA and SERCA, respectively.

As mitochondrial $\mathrm{Ca}^{2+}$ overload is a major actor triggering mitochondrial structure alteration and swelling, we analysed the mitochondrial structure in the context of Complex II defect. High-resolution imaging revealed no clear mitochondrial structure modification in Complex II-deficient cells as compared with controls (Supplementary Figure S4a). Accordingly, mitochondrial volume was also not modified on Complex II mutation or inhibition in both fibroblasts and SH-SY5Y cells (Supplementary Figure S4b). These data are in accordance with the absence of apoptosis in both models and showed also that increased mitochondrial $\mathrm{Ca}^{2+}$ content is not associated with increased mitochondrial biogenesis (as estimated by unchanged volume).

It has been shown that elevated $\mathrm{Ca}^{2+}$ signals in microdomains between mitochondria and $\mathrm{ER}^{\mathrm{Ca}^{2}}$ release sites immobilize mitochondria close to the ER, thus increasing $\mathrm{Ca}^{2+}$ transfer between the organelles. ${ }^{19}$ As we showed that Complex II mutation induced on the one hand an increased $\mathrm{ER} \mathrm{Ca}^{2+}$ leak and on the other hand an elevation of mitochondrial $\mathrm{Ca}^{2+}$ load (Figures $2 \mathrm{~b}$, d and 4), we tested whether these modifications are associated with mitochondrial movement inhibition and ER-mitochondria increased contact sites. High-resolution time-lapse imaging of the mitochondrial network revealed a significant reduction of mitochondrial movements on Complex II mutation or inhibition in both fibroblasts and SH-SY5Y cells (Figure 6a; Supplementary Table S10). Accordingly, high-resolution imaging revealed an increase of the extent of association between ER and mitochondria on Complex II deficiency (Figure 6b; Supplementary Table S11).

We then investigated the impact of $\mathrm{Ca}^{2+}$ deregulation on cellular bioenergetics and mitochondrial dysfunction related to Complex II deficiency.

Measurement of total ATP level on total cell homogenates revealed increased total $[A T P]$ in $S_{D H} A_{R 554 W}$ fibroblasts and in control fibroblasts treated with Atpenin $A 5(\sim+15 \%$ versus control) (Figure 7a; Supplementary Table S12). Similar results were obtained in SH-SY5Y cells on Complex II inhibition (Figure 7b; Supplementary Table S12). Besides the mitochondrial respiratory chain, glycolysis constitutes a second source of cellular ATP. As we showed a decrease of $[A T P]_{\text {mit }}$ (Figures 1d and $e$ ), the increased total $[A T P]$ is 
expected to be due to glycolysis activation. Indeed, glycolysis inhibition with 2-deoxy-D-glucose (a non-metabolizable analogue of glucose) leads to a decrease of total [ATP]
(Figure 7a and b; Supplementary Table S12). In agreement with this result, hyperlactataemia derived from increased glycolysis has been reported in $\mathrm{SDHA}_{\mathrm{R} 554 \mathrm{~W}}$ fibroblasts. ${ }^{20}$
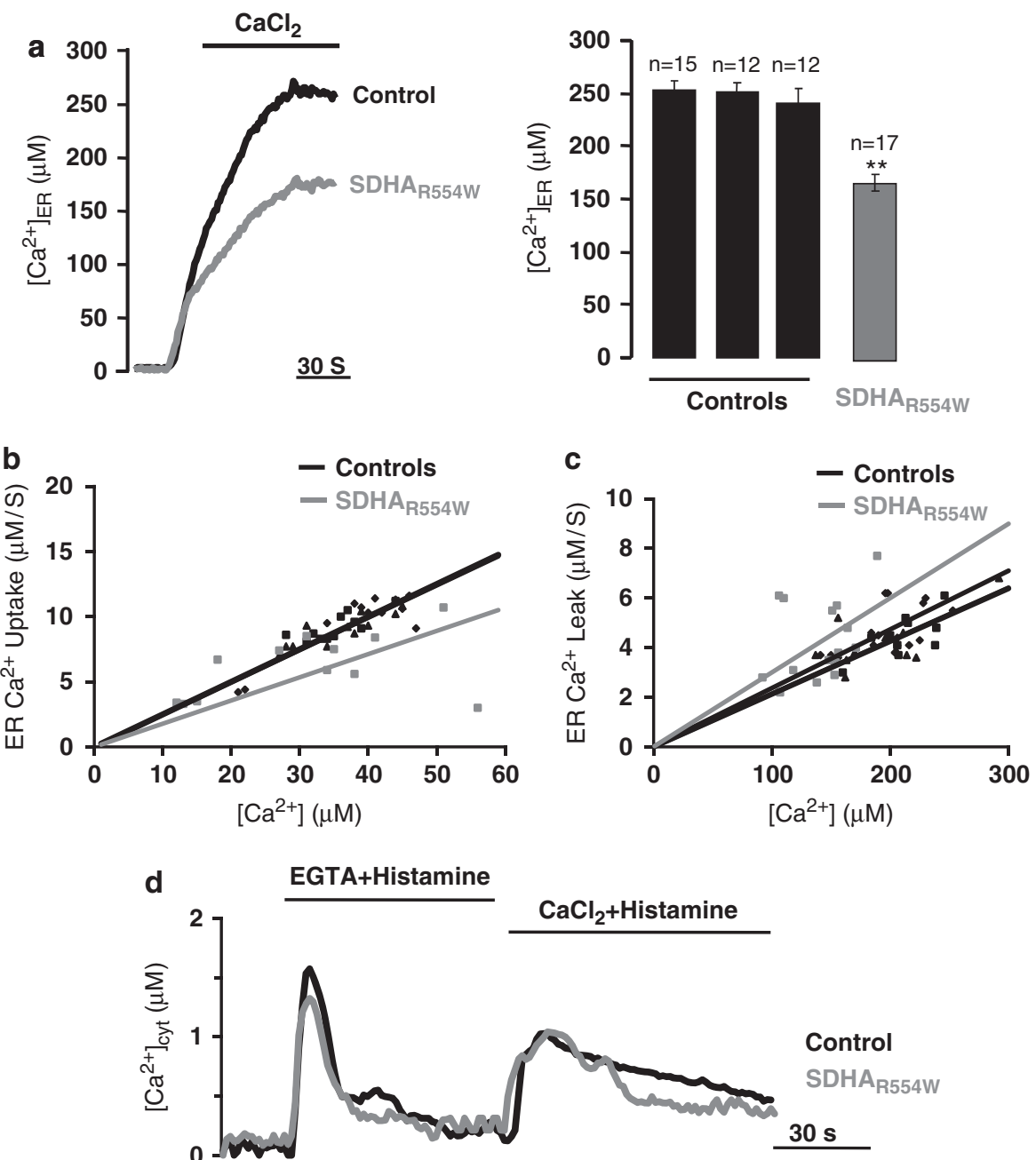

Figure 4 Increased intracellular $\mathrm{Ca}^{2+}$ signals on Complex II deficiency is associated with deregulated $\mathrm{ER} \mathrm{Ca}^{2+}$ homeostasis without a modification of calcium entry through plasma membrane. (a) Representative curves of $\mathrm{ER} \mathrm{Ca}^{2+}$ concentration $\left(\left[\mathrm{Ca}^{2+}\right]_{\mathrm{ER}}\right)$ in control and SDHA $\mathrm{R}_{554 \mathrm{~W}}$ fibroblasts. Graph: mean \pm S.E.M. The mean values \pm S.E.M. and the number of experiments are indicated in Supplementary Table S9. (b) Dependence on $\left[\mathrm{Ca}^{2+}\right]$ of the ER Ca ${ }^{2+}$ uptake rate analysed on application of $\mathrm{CaCl}_{2}$ solution (see Materials and methods for details). (c) Dependence on $\left[\mathrm{Ca}^{2+}\right]$ of the ER $\mathrm{Ca}^{2+}$ leak rate analysed on application of the SERCA inhibitor TBuBHQ (see Materials and Methods for details). (d) Capacitative $\mathrm{Ca}^{2+}$ influx analysis in control and SDHA $\mathrm{R}_{554 \mathrm{~W}}$ fibroblasts challenged first with $100 \mu \mathrm{M}$ histamine in $1 \mathrm{mM}$ EGTA to empty intracellular $\mathrm{Ca}^{2+}$ pools and then with $100 \mu \mathrm{M}$ histamine in $1 \mathrm{mM} \mathrm{CaCl}_{2}$ to activate $\mathrm{Ca}^{2+}$ entry. (a-d) Data are representative of three independent experiments. ${ }^{* *} P<0.001$ versus control

Figure 5 Complex II deficiency is associated with down-regulation of SERCA2b and PMCA expression. (a) Western-blot analyses of microsomal fraction (SERCA2b and

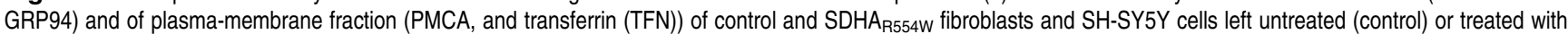
$300 \mu \mathrm{M}$ 3-NP, $100 \mathrm{nM}$ Atpenin A5 or $5 \mu \mathrm{M}$ Oligomycin for $20 \mathrm{~h}$. Quantification of SERCA2b protein level was normalized to GRP94 signal and PMCA to TFN signal and is represented in arbitrary units (AU). (b) SERCA and PMCA expression down-regulation in Complex Il-deficient cells is not linked to reduced mRNA levels. Semi-quantitative RT-PCR analysis of SH-SY5Y cells left untreated (control) or treated as in (a). The blots show the results of different cycles of the PCR of SERCA2b (24, 26 and 28 cycles), PMCA2 (32, 34 and 36 cycles) and GAPDH used as control (22, 24, 26 cycles). Quantification of three independent experiments is shown in graphs as mean \pm S.E.M., non-significant (ns) versus control. Representative blots are shown. (c) Rapid degradation of SERCA2b and PMCA2 on Complex II inhibition by 3-NP (300 $\mu$ M) or ATP synthase inhibition by Oligomycin $(5 \mu \mathrm{M})$. SH-SY5Ycells were treated with $100 \mu \mathrm{M}$ cyclohexemide (CHX) alone or in the presence of 3-NP or Oligomycin for the indicated time points. $\alpha$-tubulin was used as loading control. Quantification of three independent experiments is shown in graphs as mean \pm S.E.M., ns, non-significant, $\left({ }^{*}\right) P \geqslant 0.01$ versus untreated cells (control) considered as 1. Representative blots are shown. (d) Effect of proteasome inhibitor MG132 on SERCA2b and PMCA2 expression. After $2 \mathrm{~h}$ pre-incubation of SH-SY5Y cells with or without MG132 $(5 \mu \mathrm{M})$, cells were treated for $1 \mathrm{~h}$ with $100 \mu \mathrm{M}$ cycloheximide in the presence or not of $300 \mu \mathrm{M} 3-\mathrm{NP}$ or $5 \mu \mathrm{M}$ Oligomycin. $\alpha$-tubulin was used as loading control 
It has been recently shown that intracellular $\mathrm{Ca}^{2+}$ may activate glycolytic ATP synthesis. ${ }^{21}$ Accordingly, we showed that $\mathrm{Ca}^{2+}$ chelation by BAPTA, AM reduced total [ATP] in control and Complex II-deficient cells (Figure 7c; Supplementary Table S13). Interestingly, the extent of ATP reduction was larger in Complex II-deficient cells as compared with controls (72\% in control, 60\% in SDHA $\mathrm{R}_{554 \mathrm{~W}}$ and 65\% in Atpenin A5) (Figure 7c; Supplementary Table S13).

The data presented in Figure 1 showed an overt mitochondrial pathology on Complex II deficiency. Different

a

Fibroblasts

SH-SY5Y
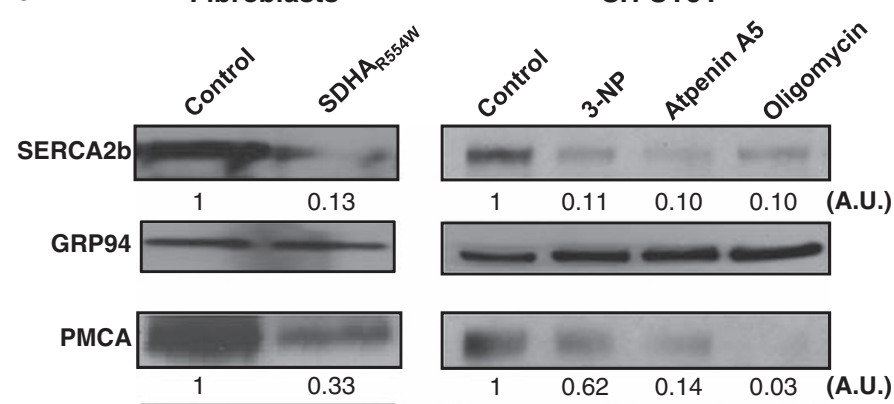

TFN
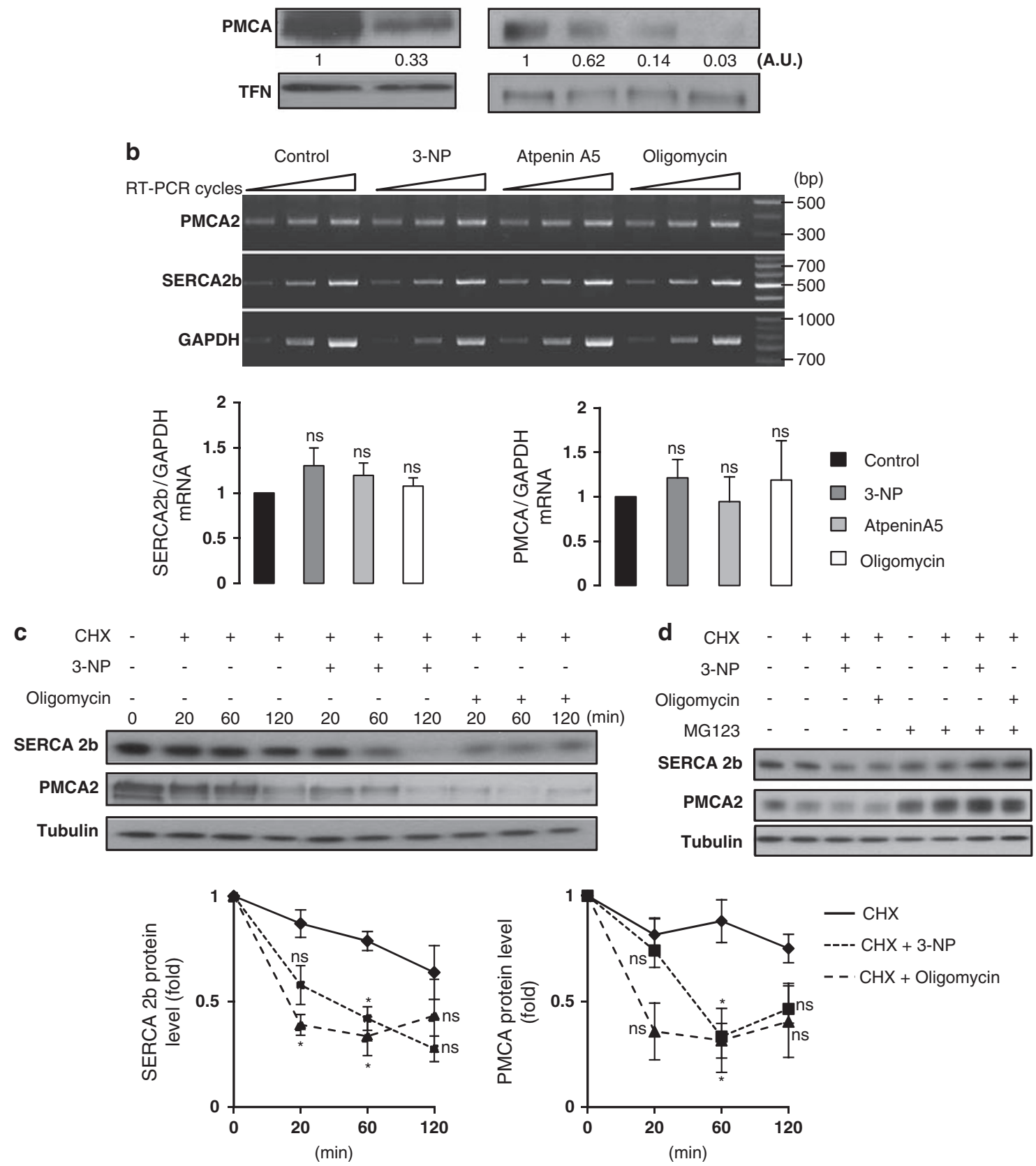
a

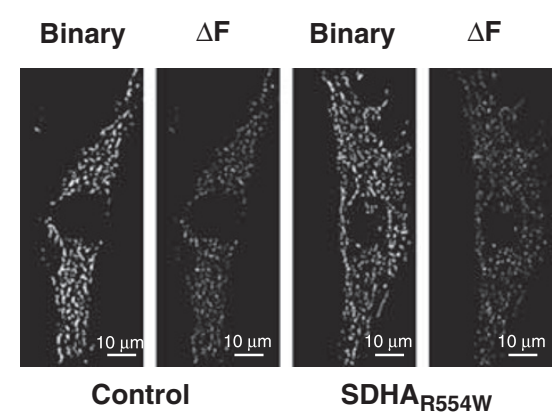

Fibroblasts
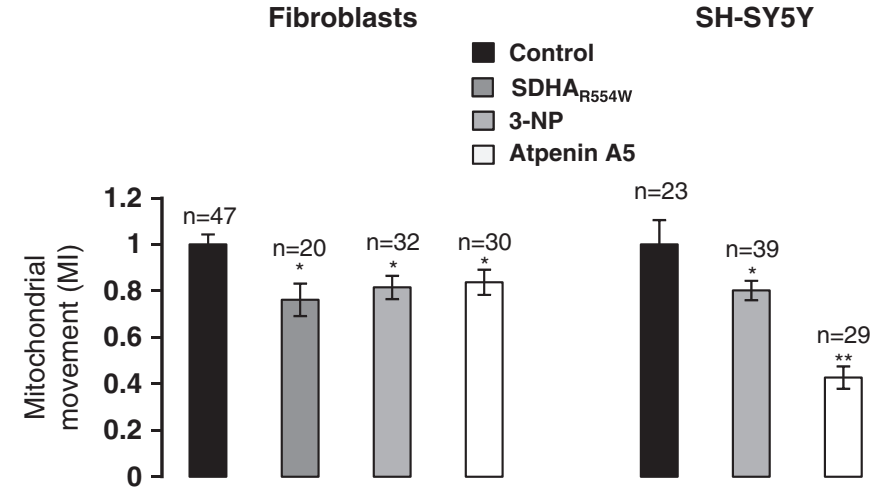

SH-SY5Y

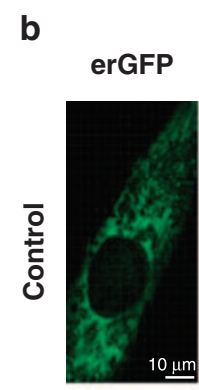

Mito
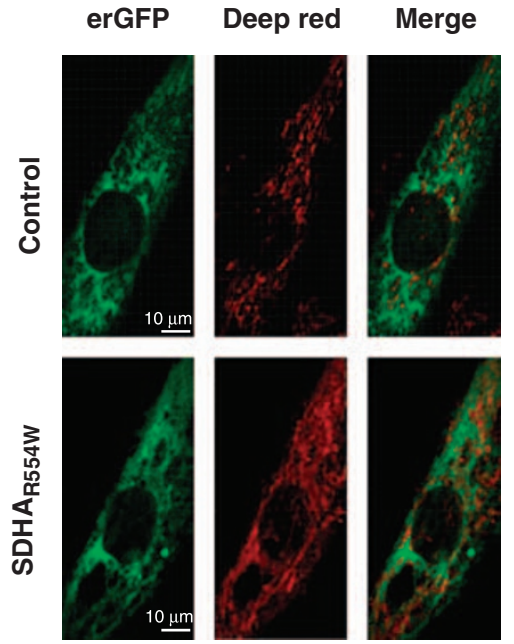
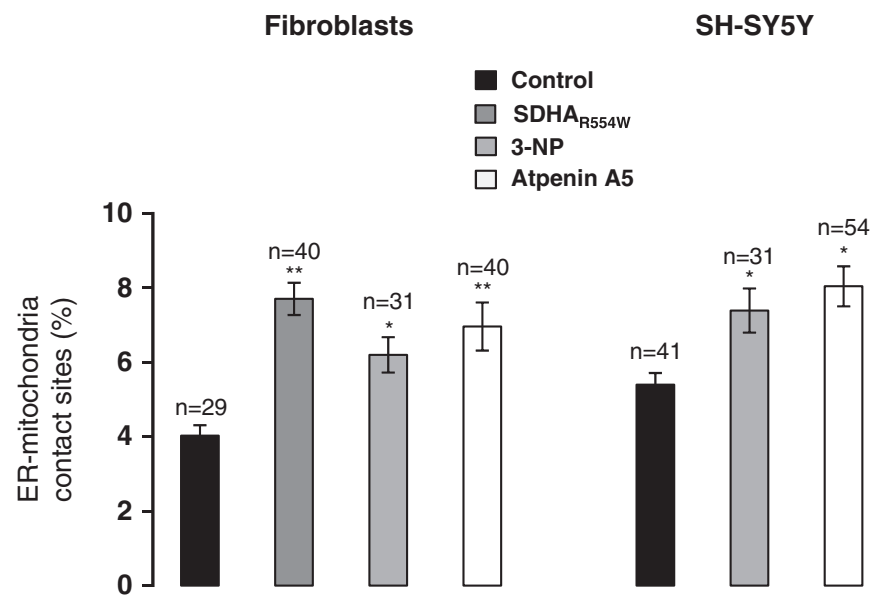

Figure 6 Mitochondrial motility and ER-mitochondria contact sites are modified on Complex II defect. (a) Mitochondrial movement index (MI) was analysed in the same conditions as in Figures $1 \mathrm{a}$ and $\mathrm{b}$ by using Mitotracker red dye. Images converted to binary files were sequentially subtracted to generate $\Delta F$. MI corresponds to the ratio of $\Delta F$ on total mitochondrial area. Data are presented as MI versus control considered as 1. MI \pm S.E.M. are shown in Supplementary Table S10. (b) ER-mitochondria contact sites were analysed in cells transfected with erGFP and loaded with MitoTracker Deep Red in the same conditions as in (a). Representative images of ER (erGFP, green), mitochondria (Mito Deep Red, red) and overlay images (Merge) are shown. Graph: quantitative analysis of the colocalization of ER and mitochondria (\% of mitochondrial volume in contact with ER).\% of ER-mitochondria contact sites \pm S.E.M. is presented in Supplementary Table S11. (a, b) Data are representative of three independent experiments. ${ }^{*} P \geqslant 0.001,{ }^{\star \star} P<0.001$ versus control

laboratories have reported the complex cross-interactions between $\Delta \psi_{\text {mit }}, \mathrm{Ca}^{2+}$ and ROS production. ${ }^{1}$ It was also shown that mitochondrial depolarization requires and is maintained by the high $\left[\mathrm{Ca}^{2+}\right]_{\text {cyt. }}{ }^{22} \mathrm{We}$ thus investigated the role of cytosolic $\mathrm{Ca}^{2+}$ overload on $\Delta \psi_{\text {mit }}$ loss linked to Complex II deficiency. As shown in Figure 7d, application of BAPTA, AM rescued mitochondrial potential in SDHA $\mathrm{R}_{\mathrm{R} 54 \mathrm{~W}}$ cells (Figure 7d; Supplementary Table S14). We assume that mitochondrial potential recovery observed in $\mathrm{SDHA}_{\mathrm{R} 554 \mathrm{~W}}$ is due to reduced mitochondrial $\mathrm{Ca}^{2+}$ uptake as a consequence of removal of $\left[\mathrm{Ca}^{2+}\right]_{c y t}$ by BAPTA, AM. Indeed, BAPTA, AM application reduced mitochondrial basal and agonist-evoked $\left[\mathrm{Ca}^{2+}\right]$ (data not shown). In accordance with this result, cell treatment with BAPTA, AM also revealed a significant reduction of $\left[\mathrm{O}_{2}^{\bullet-}\right]$ in $\mathrm{SDHA}_{\mathrm{R} 554 \mathrm{~W}}$ cells (Figure 7e; Supplementary Table S15). These findings suggest that $\mathrm{Ca}^{2+}$ overload participated to mitochondrial pathology observed in Complex II-deficient cells.

We finally addressed the question about the consequences of mitochondrial pathology linked to Complex II deficiency on cellular fate. In accordance with earlier reported data, ${ }^{23,24}$ we showed that complete Complex II inhibition (1 mM 3-NP treatment for $20 \mathrm{~h}$ ) (Supplementary Figure S1d, right panel) determined cell death (Supplementary Figure S1d, left panel), mitochondrial structure alteration (Supplementary Figure $\mathrm{S} 5 \mathrm{a})$ and reduction of mitochondrial $\mathrm{Ca}^{2+}$ load (Supplementary Figure S5b). These processes are known as markers of mitochondrial outer membrane permeabilization and swelling accompanying cell death.

\section{Discussion}

By studying fibroblasts isolated from a patient affected by Leigh's syndrome harbouring respiratory chain Complex II $\left(\mathrm{SDHA}_{\mathrm{R} 554 \mathrm{~W}}\right)$ mutation $^{13}$ and fibroblasts and neuronalderived cells chronically treated with Complex II inhibitors, we reported subcellular $\mathrm{Ca}^{2+}$ deregulations occurring before cell death and showed that Complex II deficiency induced a deep regulation of $\mathrm{Ca}^{2+}$ signalling-dependent bioenergetics and mitochondrial dysfunction, which control cellular fate. 


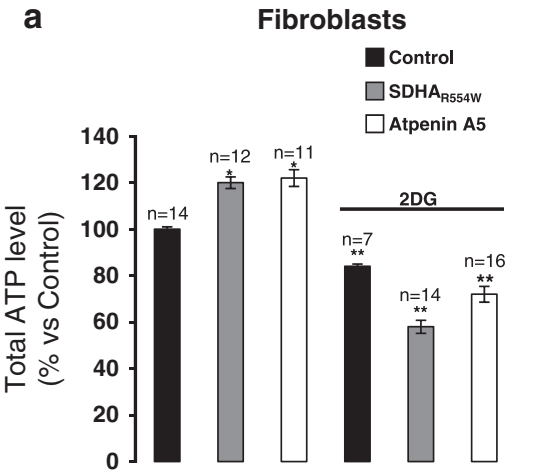

d

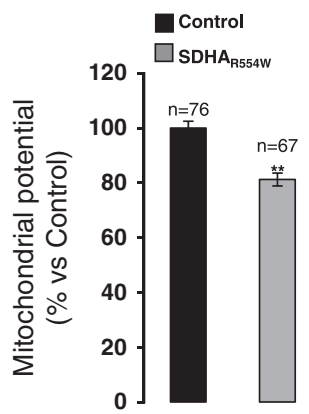

Fibroblasts

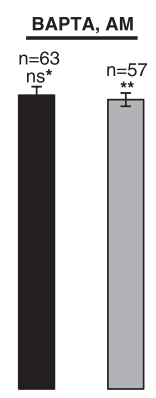

b

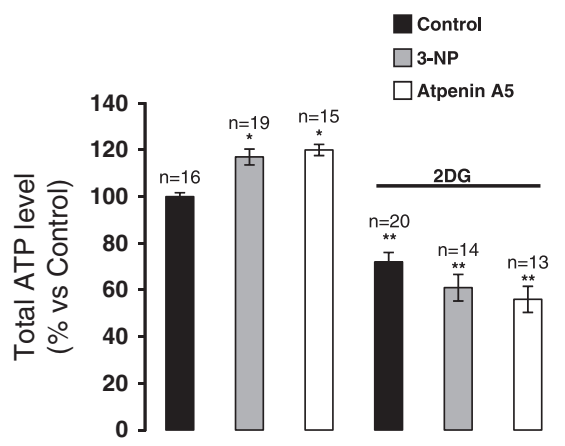

C

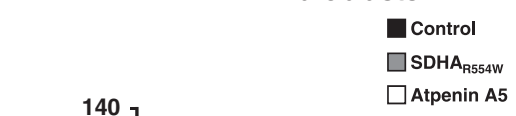

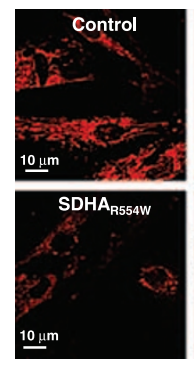

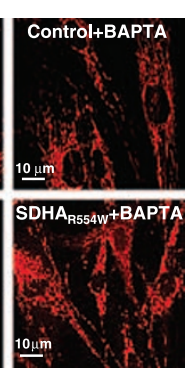

e

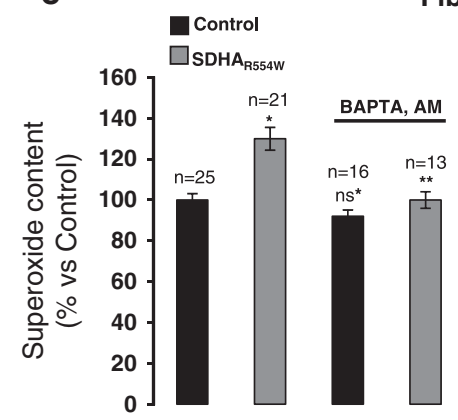

Fibroblasts

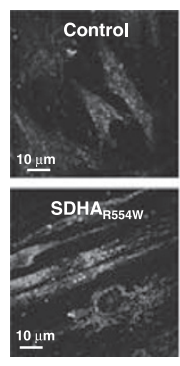

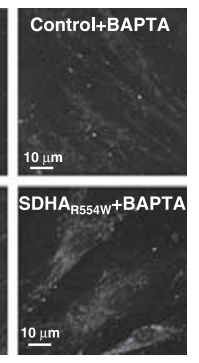

Figure 7 Mitochondrial $\mathrm{Ca}^{2+}$ overload is implicated in the modulation of cellular bioenergetics and mitochondrial dysfunction on Complex II deficiency. (a, b) Total ATP level in SDHA ${ }_{\mathrm{R} 554 \mathrm{~W}}$-mutated fibroblasts and in control fibroblasts left untreated (control) or treated with Atpenin A5 as in Figure 1a (a) and in SH-SY5Y cells left untreated (control) or treated as in Figure $1 \mathrm{~b}(\mathbf{b})$ in the presence or not of $10 \mathrm{mM}$ 2-deoxy-D-glucose (2-DG).\% of total ATP versus control \pm S.E.M. and number of experiments are

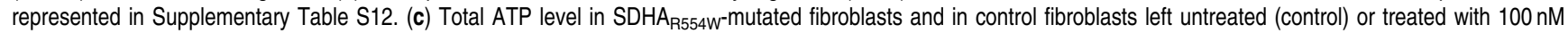
Atpenin A5 in the presence or not of $5 \mu \mathrm{M}$ BAPTA, AM for $20 \mathrm{~h}$.Percentage of total ATP versus control \pm S.E.M. and number of experiments are represented in Supplementary Table S13. (d) $\Delta \psi_{\text {mit }}$ analyses in control and SDHA $A_{\text {R554W }}$ fibroblasts left untreated or treated with BAPTA, AM as in (d). Percentage of TMRM intensity versus control \pm S.E.M. and number of experiments are represented in Supplementary Table S14. (e) Mitochondrial superoxide content quantification performed as in Figure 1c in control and $\mathrm{SDHA}_{\mathrm{R} 554 \mathrm{~W}}$ fibroblasts left untreated or treated with BAPTA-AM as in (d). The mean of MitoSOX intensity in percentage versus control \pm S.E.M. and number of experiments are represented in Supplementary Table S15. (d, e) Representative images are shown. (a-e) Data are representative of three independent experiments. ${ }^{*} P \geqslant 0.001$, ${ }^{* \star} P<0.001$ non-significant (ns) versus control or versus untreated conditions (see Supplementary Tables S13-15)

Only few studies have been focusing on the study of Complex II inhibition and none has provided a global assessment of subcellular $\mathrm{Ca}^{2+}$ signalling before cell death. These studies reported that inhibition of Complex II by 3-NP enhances basal and NMDA-induced intracellular $\left[\mathrm{Ca}^{2+}\right]$ in neurons, ${ }^{23,25,26}$ potentially leading to $\Delta \psi_{\text {mit }}$ loss, mitochondrial structure alteration, ROS production and cell death. ${ }^{23,26,27}$

The parallel and thorough investigation of subcellular $\mathrm{Ca}^{2+}$ and bioenergetics alterations on Complex II mutation or chronic inhibition allowed us to reveal the following pattern (Figure 8): Complex II deficiency is associated with the proteasome-dependent degradation of the two important $\mathrm{Ca}^{2+}$ ATPases, SERCA and PMCA thus leading to increase cytosolic $\mathrm{Ca}^{2+}$ signals. Increased $\left[\mathrm{Ca}^{2+}\right]_{\text {cyt }}$ and ER Ca ${ }^{2+}$ leak likely caused increased $\left[\mathrm{Ca}^{2+}\right]_{\text {mit }}$ through increased ER-mitochondria contact sites and mitochondrial immobilization. As $99.9 \%$ of the total matrix $\mathrm{Ca}^{2+}$ content is in bound form, ${ }^{28}$ we cannot exclude a function for an increased mitochondrial retention capacity in the observed mitochondrial $\mathrm{Ca}^{2+}$ overload (e.g. $\mathrm{Ca}^{2+}$ binding to cardiolipin, anionic phospholipids, the carboxy-anion-containing metabolites of the Krebs cycle (citrate, oxaloacetate) and inorganic phosphate ${ }^{28}$ ).

The situation in Complex II-deficient cells is particular as a large number of studies have reported reduced $\mathrm{Ca}^{2+}$ signals in different models of mitochondrial respiratory chain diseases (i.e. in MELAS: mitochondrial encephalopathy, lactic acidosis and stroke-like episodes, ${ }^{10}$ and MERRF: myoclonic epilepsy and ragged-red fibres, ${ }^{9}$ and in Complex I-mutated fibroblasts ${ }^{11}$ ). To note, our study was conducted in models before cell death thus revealing primary $\mathrm{Ca}^{2+}$ deregulation events occurring on Complex II deficiency.

We showed that cytosolic and mitochondrial $\mathrm{Ca}^{2+}$ overload linked to Complex II deficiency are likely to be due to rapid degradation of SERCA2b and PMCA2 occurring in a proteasome-dependent manner. This phenomenon is predictably related to the decreased mitochondrial ATP production, as SERCA2b and PMCA2 degradation was also observed on ATP synthase inhibition. Complex II-dependent SERCA2b and PMCA2 degradation occurs despite the slight increase of glycolysis-dependent, cytosolic [ATP] pointing out a primary function of mitochondrial ATP in the degradation process. Indeed, mitochondrial ATP is considered the major cellular 

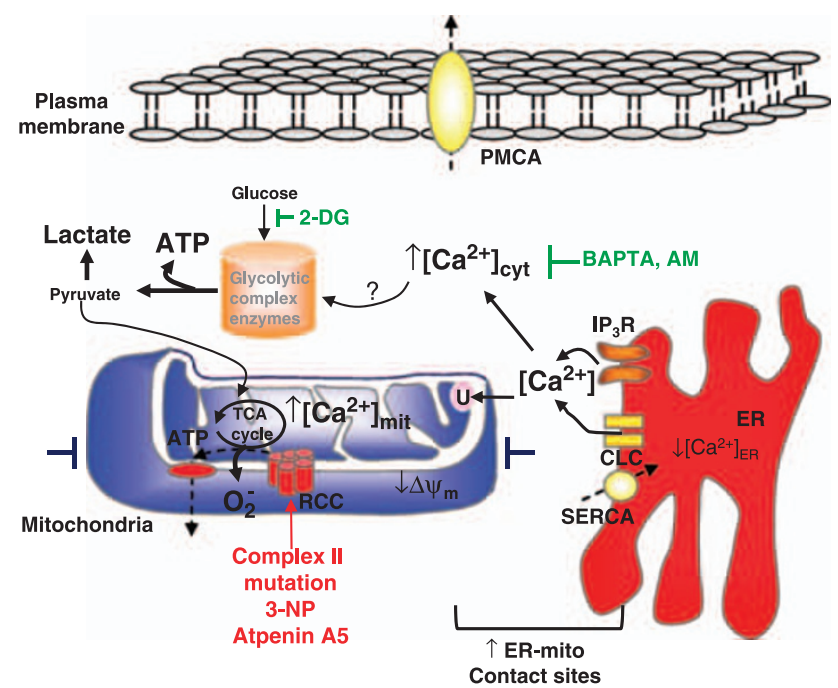

Movement inhibition

Figure 8 Schematic model representing subcellular $\mathrm{Ca}^{2+}$ deregulation, mitochondrial dysfunction and bioenergetics outcomes on Complex II mutation or inhibition. Complex II deficiency induces mitochondrial function alteration (reduced $\Delta \psi_{\text {mit }}$ and $[A T P]_{\text {mit }}$ and increased $\left.\left[\mathrm{O}_{2}^{-}\right]\right)$, and subcellular $\mathrm{Ca}^{2+}$ deregulation The increased $\left[\mathrm{Ca}^{2+}\right]_{\text {cyt }}$ is mediated by: (i) increased $\mathrm{ER} \mathrm{Ca}^{2+}$ leak; and (ii) degradation of PMCA and SERCA2b. Mitochondrial $\mathrm{Ca}^{2+}$ overload is facilitated by mitochondrial movement inhibition and increased ER-mitochondria contact sites. This leads on the one hand to mitochondrial $\mathrm{Ca}^{2+}$ overload and on the other hand to glycolysis-dependent ATP production. RCC: respiratory chain complexes. CLC: $\mathrm{Ca}^{2+}$ leak channels. U: uniporter

ATP source. Alternatively, and not exclusively, the proximity between mitochondria and plasma and/or ER membranes could explain the sensitivity of SERCA2b and PMCA2 to mitochondrial ATP production. Accordingly, the existence of ATP micro-domains beneath the plasma membrane and in ER-mitochondria contact sites has been already shown in some cell models. ${ }^{29,30}$

Proteasome-dependent degradation of SERCA2a isoform was reported in an earlier work by Ihara et al. ${ }^{31}$ Ubiquitination of PMCA1 isoform has also been detected after preconditioning ischaemia in rat cortical neuronal cultures. ${ }^{32}$ As polyubiquitylated proteins are the preferred proteasome $26 \mathrm{~S}$ substrates, we postulate that SERCA2b and PMCA2 undergo proteasome-dependent degradation after their ubiquitination.

It is known that ATP/ $\mathrm{Mg}^{2+}$ regulates the $26 \mathrm{~S}$ proteasome activity, its assembly and stability. ${ }^{33}$ However, Geng et al. ${ }^{34}$ showed that a subset of $26 \mathrm{~S}$ proteasome is activated as ATP levels decline. Thus, in the context of Complex II deficiency, mitochondrial ATP depletion may have favoured the activation of a subset of $26 S$ proteasome leading to SERCA2b and PMCA2 degradation.

Increased total ATP production has been recently reported in MELAS syndrome linked to Complex I ND5 gene mutation. ${ }^{35}$ In this study, glycolytic ATP has been shown to be consumed by mitochondria to maintain $\Delta \psi_{\text {mit. }}$ In addition, $\mathrm{Ca}^{2+}$-dependent activation of anaerobic glycolysis and increased cytosolic ATP have been recently described during apoptotic cell death. ${ }^{21}$ As our study was conducted before cell death, increased glycolysis-dependent [ATP] may be a compensatory mechanism to the decreased oxidative phosphorylation-dependent ATP production. This phenomenon is $\mathrm{Ca}^{2+}$ dependent as we showed that $\mathrm{Ca}^{2+}$ chelation by BAPTA, AM reversed glycolytic-dependent ATP production. Thus, the increase of intracellular $\mathrm{Ca}^{2+}$ signals may be considered as a first attempt to delay cellular pathology through the activation of glycolytic-dependent ATP production.

Our study revealed a double hint of $\mathrm{Ca}^{2+}$ signalling deregulation in Complex II-deficient cells as besides increasing glycolytic ATP production, $\mathrm{Ca}^{2+}$ overload favoured mitochondrial pathology. Thus, depending on their energetic needs, cells with Complex II defect may thus undergo a progressive mitochondrial dysfunction, characterized by $\Delta \psi_{\text {mit }}$ loss, $\mathrm{Ca}^{2+}$ overload and increased ROS, eventually leading to cell death (Supplementary Figure S5). As a matter of fact, neuronal loss was reported in the brain of the patient harbouring SDHA $_{\text {R554W }}$ mutation. ${ }^{36}$

\section{Materials and Methods}

Chemicals. Culture material was obtained from Invitrogen (SARL, Cergy Pontoise, France), coelenterazine, and fluorescent dyes from Molecular Probes (Invitrogen, SARL), and Atpenin A5 from Coger (eMarketLabo.com). All the other reagents and chemicals were from Sigma-Aldrich (Sigma-Aldrich, SARL, Lyon, France).

Cell culture. Fibroblasts were grown as already described. ${ }^{17}$ Human SH-SY5Y neuroblastoma cells (CRL-2266: ATCC, Manassas, VA, USA) were cultured following manufacturer's instructions.

Aequorin measurements. To bypass low transfection efficiency of fibroblasts and SH-SY5Y cells, we used the earlier described adenoviral system expressing cytosolic (AdCMVcytAEQ)-, mitochondrial (AdCMVmitAEQmut and AdCMVmitAEQwt)-, and ER (AdCMVerAEQ)-targeted aequorin probes. ${ }^{37-39}$ For infection, 20000 cells (fibroblasts) and 150000 cells (SH-SY5Y) were spotted on 13-mm coverslips, and placed $24 \mathrm{~h}$ later in contact with the appropriate virus $\left(10^{5}\right.$ infectious particles $\left./ \mathrm{ml}\right)$. Aequorin measurements were performed $48 \mathrm{~h}$ post-infection. Specific targeting of adenoviral aequorin probes to desired organelles was verified by immunohistochemistry (Supplementary Figure S6).

MitAEQ and cytAEQ were reconstituted with $5 \mu \mathrm{M}$ coelenterazine for $2 \mathrm{~h}$ in Krebs-Ringer-modified buffer (KRB: $125 \mathrm{mM} \mathrm{NaCl}, 5 \mathrm{mM} \mathrm{KCl}, 1 \mathrm{mM} \mathrm{Na}_{3} \mathrm{PO}_{4}$, $1 \mathrm{mM} \mathrm{MgSO}_{4}, 5.5 \mathrm{mM}$ glucose and $20 \mathrm{mM}$ Hepes, pH 7.4) supplemented with $1 \mathrm{mM}$ $\mathrm{CaCl}_{2}\left(\mathrm{KRB} / \mathrm{CaCl}_{2}\right)$ at $37^{\circ} \mathrm{C}$. Cytosolic and mitochondrial signals were obtained on application of $100 \mu \mathrm{M}$ Histamine (fibroblasts) or $500 \mu \mathrm{M}$ Carbachol (SH-SY5Y).

Capacitative $\mathrm{Ca}^{2+}$ entry analyses were performed by using cytosolic (AdCMVcytAEQ)-aequorin probe. Cells transferred to the luminometer were treated as specified in the legend of the figure.

For reconstitution with high efficiency of the erAEQ, the luminal $\left[\mathrm{Ca}^{2+}\right]$ of this compartment was first reduced. This was achieved by incubating the cells for $1 \mathrm{~h}$ at $4^{\circ} \mathrm{C}$ in KRB supplemented with $5 \mu \mathrm{M} \mathrm{n}$-coelenterazine, $1 \mu \mathrm{M} \mathrm{Ca}^{2+}$ ionophore ionomycin and $600 \mu \mathrm{M}$ EGTA. After this incubation, cells were extensively washed with KRB supplemented with $2 \%$ bovine serum albumin before the luminescence measurement was initiated. The ER was refilled by exposing the cells to extracellular $1 \mathrm{mM} \mathrm{CaCl}$. After reaching the steady state value, agonist-evoked $\mathrm{Ca}^{2+}$ release was initiated by application of agonists. The SERCA blocker, TBuBHQ (2, 5 -Di (tert-butyl) - 1, 4-benzohydroquinone) was used to initiate the release of stored $\mathrm{Ca}^{2+}$ and thus to analyse $\mathrm{ER} \mathrm{Ca}^{2+}$ leak. All aequorin measurements were carried out in a purpose built luminometer. The experiments were terminated by lysis of the cells with $100 \mu \mathrm{M}$ digitonin in a hypotonic $\mathrm{Ca}^{2+}$-rich solution $(10 \mathrm{mM}$ $\mathrm{CaCl}_{2}$ in $\mathrm{H}_{2} \mathrm{O}$ ), thus discharging the remaining aequorin pool. The light signal was collected and calibrated into $\left[\mathrm{Ca}^{2+}\right]$ values, as earlier described. ${ }^{18}$ On the basis of the experimental traces, the maximum rates of $\mathrm{ER} \mathrm{Ca}^{2+}$ uptake were measured from the first derivative of the ascending refilling phase obtained after $\mathrm{CaCl}_{2}$ addition, and the maximum rates of $\mathrm{ER} \mathrm{Ca}^{2+}$ leak were measured from the first derivative of the curve on addition of TBuBHQ using Origin 5 software. Fitting of the curve was performed using Microsoft Excel software. 
ATP measurements. Mitochondrial [ATP] was measured after transient transfection of mitochondrial-targeted luciferase probe (mit-LUC). Briefly, cell luminescence was measured in the same luminometer used for aequorin measurements. Cells were perfused with $\mathrm{KRB}$, supplemented with $1 \mathrm{mM} \mathrm{CaCl}$ and then shifted to the same buffer supplemented with $20 \mu \mathrm{M}$ luciferin. At the end of each experiment, digitonin-permeabilized cells were perfused with an intracellular buffer (IB) $\left(140 \mathrm{mM} \mathrm{KCl}, 5 \mathrm{mM} \mathrm{NaCl}, 1 \mathrm{mM} \mathrm{K}_{3} \mathrm{HPO}_{4}, 2 \mathrm{mM} \mathrm{MgSO}_{4}, 20 \mathrm{mM}\right.$ Hepes, $\mathrm{pH} 7.05$ at $37^{\circ} \mathrm{C}$ ) supplemented with $100 \mu \mathrm{M}$ EGTA, $20 \mu \mathrm{M}$ luciferin and $5 \mathrm{mM}$ of ATP/ $\mathrm{MgCl}_{2}$. Mitochondrial basal ATP level was normalized to the maximum luciferase signal obtained after cell permeabilization with digitonin and considered as $100 \%$. For total ATP level, we used ATP Bioluminescence Assay kit CL II (Roche, Diagnostics, Meylan, France).

Measurements of cytosolic and mitochondrial basal $\left[\mathrm{Ca}^{2+}\right]$ concentrations. Cells spotted on 24-mm coverslips were loaded with $5 \mu \mathrm{M}$ Fluo-4, AM (cytosolic $\mathrm{Ca}^{2+}$ probe) or $1 \mu \mathrm{M}$ X-Rhod-1, AM (mitochondrial $\mathrm{Ca}^{2+}$ probe) prepared in a $\mathrm{KRB} / 1 \mathrm{mM} \mathrm{CaCl} \mathrm{Ca}_{2}$ at $37^{\circ} \mathrm{C}$ for $30 \mathrm{~min}$. After a brief washout, time-lapse images were acquired on a Zeiss LSM 510 confocal microscope (Carl Zeiss, S.A.S. LePecq, France). We calibrated Fluo-4, AM and X-Rhod-1, AM probes as recently described by our group ${ }^{18}$ and provided absolute basal $\mathrm{Ca}^{2+}$ values in the cytosol and the mitochondria. After a control period (providing the basal fluorescent intensity, $F$, $F_{\max }$ was obtained on application of ionomycin/ $\mathrm{Ca}^{2+}$ solution (ionomycin: $10 \mu \mathrm{M}$ and $\mathrm{Ca}^{2+}: 50 \mathrm{mM}$ ). Then, the $F_{\min }$ value was obtained on addition of $10 \mathrm{mM}$ EGTA solution in the same bath. We used the equation provided by the manufacturer $\left[\mathrm{Ca}^{2+}\right]_{\text {rree }}=K_{\mathrm{d}}{ }^{*}\left(\left(F-F_{\min }\right) /\left(F_{\max }-F\right)\right)$ and the $K_{\mathrm{d}}$ value of $700 \mathrm{nM}$ for X-Rhod-1, AM and of $345 \mathrm{nM}$ for Fluo-4, AM.

Measurements of mitochondrial superoxide concentration. MitoSOX red is a novel fluorogenic dye for highly selective detection of superoxide in the mitochondria of living cells. Cells spotted on 24-mm coverslips were loaded with $5 \mu \mathrm{M}$ MitoSOX red prepared in a $\mathrm{KRB} / 1 \mathrm{mM} \mathrm{CaCl} 2$ at $37^{\circ} \mathrm{C}$ for $30 \mathrm{~min}$. After a brief washout, Z-stack images were acquired on a Zeiss LSM 510 confocal microscope (Carl Zeiss). Dye intensity was quantified on maximal projection of Z-stack images after thresholding, using the Zeiss LSM and ImageJ softwares. We presented data as mean fluorescence intensity of oxidized MitoSOX. We assume that MitoSOX probe give a semi-quantitative detection and not an absolute estimation of mitochondrial superoxide value. Importantly, as control, we used the ROS scavenger PDCT to show the specificity of this probe.

Imaging analyses. For the measurement of mitochondrial movements or mitochondrial potential $\left(\Delta \psi_{\text {mit }}\right)$, images were acquired on a Zeiss LSM 510 confocal microscope after loading the cells with $10 \mathrm{nM}$ Mitotracker red (movement analysis) or $20 \mathrm{nM}$ TMRM $\left(\Delta \psi_{\mathrm{m}}\right.$ analysis) in $\mathrm{KRB} / 1 \mathrm{mM} \mathrm{CaCl}{ }_{2}$ at $37^{\circ} \mathrm{C}$ for $30 \mathrm{~min}$.

For mitochondria movement analysis, time series images were taken with a time interval of $5 \mathrm{~s}$ between each image. Images were 2D-deconvolved, median filtered, thresholded and clipped to 8-bit binary images using Metamorph (Universal Imaging) software. Using the stack-T-functions/Delta-F-down plugin of the WCIF ImageJ software (http://www.uhnres.utoronto.ca/facilities/wcif/), pixels in each frame were subtracted from the next frame. The resulting images were quantified by measuring the total area of object on the binary and $\Delta F$ images by the integrated morphometry analysis function of the Metamorph software. Data were normalized as the ratio of $\Delta F$ area values over the total area of the original binary images for each cell. This parameter is referred to as the mitochondrial movement index. ${ }^{18}$ Binarization and normalization were applied to avoid artefacts eventually arising from changes of intensity and focal plane.

To obtain normalized TMRM fluorescence signal, time-lapse images were acquired on a Zeiss LSM 510 confocal microscope. Images were acquired before and after application of $10 \mu \mathrm{M}$ mitochondrial uncoupler FCCP. To show specific TMRM binding, measurements were routinely corrected for residual TMRM fluorescence after full $\Delta \psi_{\text {mit }}$ collapse with FCCP. Basal TMRM signal was normalized to the remaining signal obtained on FCCP application and presented as $f f f_{0}$ where $f$ is the mean of basal TMRM intensity along $10 \mathrm{~s}$ in the plateau phase and $f_{0}$ is the mean of TMRM intensity along the baseline after FCCP application.

For analyses of ER-mitochondria contact sites, cells were transfected with erGFP and loaded with Mitotracker Deep Red. The spectral properties of these two fluorochromes allow specific identification of the two compartments and quantification of contact sites. 16-bit images were acquired with a pixel size equal or lower to the maximal resolution of the $63 \mathrm{X}$ objective to allow optimal detection of colocalized pixels on the stage of a Leica SP5 confocal microscope. ER and mitochondria colocalization was calculated as the number of voxels (volume pixels) occupied by both signals (i.e. erGFP and Mitotracker Deep Red) over all voxels occupied by the mitochondria (Mitotracker Deep Red signal) in thresholded images using Imaris software.

Protein preparation and western-blot analyses. Plasma membrane and microsomal fractions were isolated as already described. ${ }^{18,40}$ SDS-PAGE was then performed. The signal was revealed using ECL Plus western-blot detection reagent (Amersham Biosciences, Orsay, France).

For the experiments shown in Figures $5 \mathrm{c}$ and $\mathrm{d}$, membrane fraction obtained as already described ${ }^{18}$ was used to reveal both SERCA and PMCA. Protein synthesis was inhibited using $100 \mu \mathrm{M} \mathrm{CHX}$ alone or in the presence of $300 \mu \mathrm{M}$ 3-NP or $5 \mu \mathrm{M}$ Oligomycin for the indicated time points. Proteasome-dependent degradation of SERCA2b and PMCA2 was assessed using proteasome inhibitor MG132. After $2 \mathrm{~h}$ pre-incubation of SH-SY5Y cells with or without MG132 $(5 \mu \mathrm{M})$, cells were treated for $1 \mathrm{~h}$ with $100 \mu \mathrm{M} \mathrm{CHX}$ in the presence or not of $300 \mu \mathrm{M}$ 3-NP or $5 \mu \mathrm{M}$ Oligomycin. Loading control was assessed using $\alpha$-tubulin, GRP94 as a marker of a resident ER protein and cadherin as a marker of a resident plasma-membrane protein. Similar result was obtained using these loading controls. Only the result of $\alpha$-tubulin is shown.

RNA extraction and RT-PCR analysis. Total RNA was extracted using RNeasy Mini kit (Qiagen, Courtaboeuf, France); $1 \mu \mathrm{g}$ of total RNA was used for reverse transcription using High-Capacity cDNA Archive kit (Applied Biosystems, Courtaboeuf, France) with random hexamer primers according to the manufacturer's protocol. The final reaction volume was $25 \mu \mathrm{l}$. The reaction tubes were incubated at $25^{\circ} \mathrm{C}$ for $10 \mathrm{~min}, 120 \mathrm{~min}$ at $37^{\circ} \mathrm{C}$ and $5 \mathrm{~min}$ at $85^{\circ} \mathrm{C}$. The primers for PCR for PMCA2 transcript were forward: TCCCGACC AGCAGACTCAAGTT, reverse: CGAGTTCTGCTTGAGCGCGG (fragment size: $350 \mathrm{bp}$ ). For SERCA $2 \mathrm{~b}$ transcript, the following primers were used: forward: TTTCCTACAGTGTAAAGAGGACAACC, reverse: AGACCAGAACATATCGCTA AAGTT (fragment size: $514 \mathrm{bp}$ ). PMCA and SERCA2b transcript levels were normalized to GAPDH transcript level amplified using forward: CTTCATTG ACCTCAACTACATGGT, reverse: CTCAGTGTAGCCCAGGATGCCCTT (fragment size: $727 \mathrm{bp})$. PCR was performed using $0.5 \mu \mathrm{l}$ of the reverse transcription mixture in a final volume of $50 \mu \mathrm{l}$ containing: $1 \times$ Green GoTaq buffer, primers $(10 \mu \mathrm{M}$ each) and Gren Go Taq Hot start polymerase (2.5 U) and dNTP (10 mM each). PCR amplification cycles were run using a thermal cycler (PerkinElmer, Courtaboeuf, France) as following: denaturation at $95^{\circ} \mathrm{C}, 5 \mathrm{~min}$; annealing at $60^{\circ} \mathrm{C}, 1 \mathrm{~min}$; extension at $72^{\circ} \mathrm{C}, 1 \mathrm{~min}$, and heating at $72^{\circ} \mathrm{C}, 10 \mathrm{~min}$. For semi-quantitative PCR, three different amplification cycles were used; see figure legend. Relative signal intensities were quantified using $\mathrm{NIH}$ Image $\mathrm{J}$ software and are shown in graphs.

Statistical analyses. The results are reported from at least three different experiments. Statistical analyses were performed using ANOVA. Bonferroni's post hoc analysis was subsequently performed on ANOVA results to determine significance. Bonferroni's $t$-test was calculated versus respective control (Supplementary Tables S1-11) and graphs in Figure 5 or all pairwise (Supplementary Tables S12-15).

\section{Conflict of interest}

The authors declare no conflict of interest.

Acknowledgements. High-resolution imaging analyses were performed in Pasteur institute (PFID), Paris, France. Fluorescence imagery analyses were performed in the imaging core facility of Necker-Enfants Malades, Paris V University, France. We thank the vector core of the university Hospital of Nantes supported by the association Française contre les myopathies (AFM) for producing the Adenovirus vectors. This work was supported by grants from INSERM (Institut National de Santé et Recherche Médicale), AFM (11456 and 13291) and la Fondation pour la Recherche Médicale (FRM) (DEQ20071210550). C Caspersen was supported by 'region lle de France' postdoctoral fellowship. M Chami was supported by an INSERM young researcher contract and by the Italian Institute of Technology funds. E Mbaya was supported by a doctoral fellowship from Congo Ministry. We gratefully acknowledge the Ecole de I'INSERM for supporting the MD-PhD curriculum of B Oulès, GAR was supported by grants from the Welcome trust (081958/Z/07/Z), MRC (90401641), NIH (DK071962-01) and EU (FP6 'SAVEBETA'). MP is supported by Muscular Dystrophy Association and Kennedy Disease Association Grants. 
1. Brookes PS, Yoon Y, Robotham JL, Anders MW, Sheu SS. Calcium, ATP, and ROS: a mitochondrial love-hate triangle. Am J Physiol Cell Physiol 2004; 287: C817-C833.

2. Hajnoczky G, Hager R, Thomas AP. Mitochondria suppress local feedback activation of inositol 1,4, 5-trisphosphate receptors by Ca2+. J Biol Chem 1999; 274: 14157-14162.

3. McCormack JG, Halestrap AP, Denton RM. Role of calcium ions in regulation of mammalian intramitochondrial metabolism. Physiol Rev 1990; 70: 391-425.

4. Benit P, Slama A, Cartault F, Giurgea I, Chretien D, Lebon S et al. Mutant NDUFS3 subunit of mitochondrial complex I causes Leigh syndrome. J Med Genet 2004; 41 : 14-17.

5. Lebon S, Minai L, Chretien D, Corcos J, Serre V, Kadhom N et al. A novel mutation of the NDUFS7 gene leads to activation of a cryptic exon and impaired assembly of mitochondrial complex I in a patient with leigh syndrome. Mol Genet Metab 2007; 92 . 104-108.

6. Pagnamenta AT, Hargreaves IP, Duncan AJ, Taanman JW, Heales SJ, Land JM et al. Phenotypic variability of mitochondrial disease caused by a nuclear mutation in complex II. Mol Genet Metab 2006; 89: 214-221.

7. Zhu Z, Yao J, Johns T, Fu K, De Bie I, Macmillan C et al. SURF1, encoding a factor involved in the biogenesis of cytochrome $\mathrm{C}$ oxidase, is mutated in Leigh syndrome. Nat Genet 1998; 20: 337-343.

8. Schon EA, Santra S, Pallotti F, Girvin ME. Pathogenesis of primary defects in mitochondrial ATP synthesis. Semin Cell Dev Biol 2001; 12: 441-448.

9. Brini M, Pinton P, King MP, Davidson M, Schon EA, Rizzuto R. A calcium signaling defect in the pathogenesis of a mitochondrial DNA inherited oxidative phosphorylation deficiency. Nat Med 1999; 5: 951-954.

10. Moudy AM, Handran SD, Goldberg MP, Ruffin N, Karl I, Kranz-Eble P et al. Abnormal calcium homeostasis and mitochondrial polarization in a human encephalomyopathy. Proc Natl Acad Sci USA 1995; 92: 729-733.

11. Visch HJ, Koopman WJ, Leusink A, van Emst-de Vries SE, van den Heuvel LW, Willems $\mathrm{PH}$ et al. Decreased agonist-stimulated mitochondrial ATP production caused by a pathological reduction in endoplasmic reticulum calcium content in human complex I deficiency. Biochim Biophys Acta 2006; 1762: 115-123.

12. Ackrell BA. Progress in understanding structure-function relationships in respiratory chain complex II. FEBS Lett 2000; 466: 1-5.

13. Bourgeron $T$, Rustin $P$, Chretien D, Birch-Machin M, Bourgeois M, Viegas-Pequignot $E$ et al. Mutation of a nuclear succinate dehydrogenase gene results in mitochondrial respiratory chain deficiency. Nat Genet 1995; 11: 144-149.

14. Huang LS, Sun G, Cobessi D, Wang AC, Shen JT, Tung EY et al. 3-nitropropionic acid is a suicide inhibitor of mitochondrial respiration that, upon oxidation by complex II, forms a covalent adduct with a catalytic base arginine in the active site of the enzyme. J Biol Chem 2006; 281: 5965-5972

15. Miyadera H, Shiomi K, Ui H, Yamaguchi Y, Masuma R, Tomoda H et al. Atpenins, potent and specific inhibitors of mitochondrial complex II (succinate-ubiquinone oxidoreductase). Proc Natl Acad Sci USA 2003; 100: 473-477.

16. Echtay KS, Roussel D, St-Pierre J, Jekabsons MB, Cadenas S, Stuart JA et al. Superoxide activates mitochondrial uncoupling proteins. Nature 2002; 415: 96-99.

17. Geromel V, Kadhom N, Cebalos-Picot I, Ouari O, Polidori A, Munnich A et al. Superoxideinduced massive apoptosis in cultured skin fibroblasts harboring the neurogenic ataxia retinitis pigmentosa (NARP) mutation in the ATPase- 6 gene of the mitochondrial DNA. Hum Mol Genet 2001; 10: 1221-1228

18. Chami M, Oules B, Szabadkai G, Tacine R, Rizzuto R, Paterlini-Brechot P. Role of SERCA1 truncated isoform in the proapoptotic calcium transfer from ER to mitochondria during ER stress. Mol Cell 2008; 32: 641-651.

19. Yi M, Weaver D, Hajnoczky G. Control of mitochondrial motility and distribution by the calcium signal: a homeostatic circuit. J Cell Biol 2004; 167: 661-672.

20. Birch-Machin MA, Marsac C, Ponsot G, Parfait B, Taylor RW, Rustin P et al. Biochemical investigations and immunoblot analyses of two unrelated patients with an isolated deficiency in complex II of the mitochondrial respiratory chain. Biochem Biophys Res Commun 1996; 220: 57-62.
21. Zamaraeva MV, Sabirov RZ, Manabe K, Okada Y. Ca(2+)-dependent glycolysis activation mediates apoptotic ATP elevation in HeLa cells. Biochem Biophys Res Commun 2007; 363: 687-693.

22. Abramov AY, Duchen MR. Mechanisms underlying the loss of mitochondrial membrane potential in glutamate excitotoxicity. Biochim Biophys Acta 2008; 1777: 953-964.

23. Liot G, Bossy B, Lubitz S, Kushnareva Y, Sejbuk N, Bossy-Wetzel E. Complex II inhibition by 3-NP causes mitochondrial fragmentation and neuronal cell death via an NMDA- and ROS-dependent pathway. Cell Death Differ 2009; 16: 899-909.

24. Lim D, Fedrizzi L, Tartari M, Zuccato C, Cattaneo E, Brini M et al. Calcium homeostasis and mitochondrial dysfunction in striatal neurons of Huntington disease. J Biol Chem 2008; 283: 5780-5789.

25. Calabresi $\mathrm{P}$, Gubellini $\mathrm{P}$, Picconi $\mathrm{B}$, Centonze D, Pisani $\mathrm{A}$, Bonsi $\mathrm{P}$ et al. Inhibition of mitochondrial complex II induces a long-term potentiation of NMDA-mediated synaptic excitation in the striatum requiring endogenous dopamine. J Neurosci 2001; 21: 5110-5120.

26. Nasr P, Gursahani HI, Pang Z, Bondada V, Lee J, Hadley RW et al. Influence of cytosolic and mitochondrial $\mathrm{Ca2}+$, ATP, mitochondrial membrane potential, and calpain activity on the mechanism of neuron death induced by 3-nitropropionic acid. Neurochem Int 2003; 43 89-99.

27. Rosenstock TR, Carvalho AC, Jurkiewicz A, Frussa-Filho R, Smaili SS. Mitochondrial calcium, oxidative stress and apoptosis in a neurodegenerative disease model induced by 3-nitropropionic acid. J Neurochem 2004; 88: 1220-1228.

28. Spat A, Szanda G, Csordas G, Hajnoczky G. High- and low-calcium-dependent mechanisms of mitochondrial calcium signalling. Cell Calcium 2008; 44: 51-63.

29. Kennedy HJ, Pouli AE, Ainscow EK, Jouaville LS, Rizzuto R, Rutter GA. Glucose generates sub-plasma membrane ATP microdomains in single islet beta-cells. Potential role for strategically located mitochondria. J Biol Chem 1999; 274: 13281-13291.

30. Kaasik A, Veksler V, Boehm E, Novotova M, Minajeva A, Ventura-Clapier R. Energetic crosstalk between organelles: architectural integration of energy production and utilization. Circ Res 2001; 89: 153-159.

31. Ihara $\mathrm{Y}$, Kageyama K, Kondo $\mathrm{T}$. Overexpression of calreticulin sensitizes SERCA2a to oxidative stress. Biochem Biophys Res Commun 2005; 329: 1343-1349.

32. Meller R, Thompson SJ, Lusardi TA, Ordonez AN, Ashley MD, Jessick V et al. Ubiquitin proteasome-mediated synaptic reorganization: a novel mechanism underlying rapid ischemic tolerance. J Neurosci 2008; 28: 50-59.

33. Babbitt SE, Kiss A, Deffenbaugh AE, Chang YH, Bailly E, Erdjument-Bromage $\mathrm{H}$ et al. ATP hydrolysis-dependent disassembly of the $26 \mathrm{~S}$ proteasome is part of the catalytic cycle. Cell 2005; 121: 553-565.

34. Geng Q, Romero J, Saini V, Baker TA, Picken MM, Gamelli RL et al. A subset of $26 \mathrm{~S}$ proteasomes is activated at critically low ATP concentrations and contributes to myocardial injury during cold ischemia. Biochem Biophys Res Commun 2009; 390: 1136-1141.

35. McKenzie M, Liolitsa D, Akinshina N, Campanella M, Sisodiya S, Hargreaves I et al. Mitochondrial ND5 gene variation associated with encephalomyopathy and mitochondrial ATP consumption. J Biol Chem 2007; 282: 36845-36852.

36. Burgeois M, Goutieres F, Chretien D, Rustin P, Munnich A, Aicardi J. Deficiency in complex II of the respiratory chain, presenting as a leukodystrophy in two sisters with Leigh syndrome. Brain Dev 1992; 14: 404-408.

37. Ainscow EK, Rutter GA. Mitochondrial priming modifies Ca2+ oscillations and insulin secretion in pancreatic islets. Biochem J 2001; 353 (Part 2): 175-180.

38. Mitchell KJ, Pinton $P$, Varadi A, Tacchetti $C$, Ainscow EK, Pozzan $T$ et al. Dense core secretory vesicles revealed as a dynamic $\mathrm{Ca}(2+)$ store in neuroendocrine cells with a vesicle-associated membrane protein aequorin chimaera. J Cell Biol 2001; 155: 41-51.

39. Mitchell KJ, Tsuboi T, Rutter GA. Role for plasma membrane-related Ca2+-ATPase-1 (ATP2C1) in pancreatic beta-cell Ca2+ homeostasis revealed by RNA silencing. Diabetes 2004; 53: 393-400.

40. Chami M, Ferrari D, Nicotera $P$, Paterlini-Brechot $P$, Rizzuto R. Caspase-dependent alterations of $\mathrm{Ca} 2+$ signaling in the induction of apoptosis by hepatitis $\mathrm{B}$ virus $\mathrm{X}$ protein J Biol Chem 2003; 278: 31745-31755.

\section{Supplementary Information accompanies the paper on Cell Death and Differentiation website (http://www.nature.com/cdd)}

